\title{
Surgical Treatment of Supratentorial Glioma in Eloquent Areas
}

\author{
Andrea Talacchi ${ }^{1}$, Giovanna Maddalena Squintani ${ }^{2}$, Barbara Santini ${ }^{1}$, \\ Francesca Casagrande 3 , Francesco Procaccio ${ }^{3}$, Franco Alessandrini', \\ Giada Zoccatelli', Vincenzo Tramontano', \\ Aurel Hasanbelliu ${ }^{1}$ and Massimo Gerosa ${ }^{1}$ \\ ${ }^{1}$ Institute of Neurosurgery, \\ ${ }^{2}$ Neurological Unit, Department of Neuroscience; \\ ${ }^{3}$ Neurosurgical Intensive Care Unit, Department of Emergency and Intensive Care; \\ ${ }^{4}$ Neuroradiological Unit, Department of Radiology; \\ University Hospital, Verona, \\ Italy
}

\section{Introduction}

Awake surgery (AS) and cortical mapping have gained wider acceptance for a variety of reasons: new anesthetic agents, improved surgical techniques, increasing use of functional magnetic resonance (fMRI), and growing interest in brain mapping as shown by refinements and upgrading of imaging techniques, such as magnetoencephalography, evoked responses potentials, high density electroencephalography, positron emission tomography (PET), and optical imaging among others (Bookheimer et al., 1997; Nariai et al., 2005; Papanicolau et al., 1999; Pouratian et al., 2002; Ruge et al., 1999; Rutten et al., 1999; Simos et al., 1999). Information technology and image-guided surgery have prompted researchers to compare non-invasive versus invasive mapping while the patient is awake (Hill et al., 2000; Kamada et al., 2007; Rutten et al., 2002). Cortical mapping has rapidly evolved, but the technical characteristics of electrocortical stimulation (ECS) have remained essentially the same since Penfield's time and it is still considered the gold standard for mapping language (Fitzgerald et al., 1997; Pouratian et al., 2004; Weidemayer et al., 2004). During cortical stimulation, task disruption is taken to indicate that the underlying cortex is essential for task performance. What has changed is the increasing feasibility of mapping the brain in vivo in a way that is safe and acceptable for the patient, and the opportunity to use a broad variety of selective tasks in standardized conditions (Bulsara et al., 2005; Serletis \& Bernstein, 2007; Sielbergeld et al., 1992). This has stimulated translational research and cooperation between neuroscientists and neurosurgeons from the basic sciences to clinical applications.

\subsection{Historical background}

Direct ECS has been used in Neurosurgery since 1930, first by Foerster, and then later by Penfield and colleagues (Foerster, 1931; Penfield \& Boldrey, 1937; Penfield \& Erickson, 1942; 
Penfield \& Rasmussen, 1950). In recent years, intraoperative ECS has been adopted for the identification and preservation of language function and motor pathways. Of note is that while cortical mapping was originally applied to epilepsy surgery where resection is essentially limited to the cortex, its indications were later extended to tumor surgery which involves the white matter. Whether these differences result in different clinical and operative settings is unclear and there exist mixed situations between the two extremes. The pathology that benefits most from AS is low-grade glioma (LGG). LGGs pose a considerable challenge in that they have characteristics of both epilepsy and tumors, with a long history that could influence neurofunctional anatomy in patients presenting normal neurological findings (Duffau et al., 2005; Duffau, 2005b, 2006a, 2006b, 2007). Importantly, tumor surgery and epilepsy surgery differ as to the aims of treatment: minimizing neurological sequelae is only one aspect, which can be tailored to lesion characteristics, as determined by clinical and instrumental studies. Basically, the two pathologies differ in symptoms and impairment. Improvement of preoperative clinical impairment and radical tumor resection are the endpoints for tumor surgery, while improvement of preoperative performance is the end-point in epilepsy treatment (Buckner, 2003; Hamberger et al., 2007). In glioma surgery, the definitive clinical advantages are broader indications for tumor removal, higher rate of radical tumor resection, and lower rate of postoperative impairment (Duffau 2005a,b).

\subsection{Aim of brain mapping}

In surgical treatment of cerebral gliomas the goals are to obtain complete tumor removal to the extent the nature of the pathology allows and to accomplish this without injuring normal anatomic structures (Yasargil, 1996a). Although LGGs and high-grade gliomas (HGGs) are distinct in biological features, clinical behavior and outcomes, understanding the effect of surgery remains equally important for both. This is especially true for lesions in areas of eloquence, where the proximity of critical pathways can present a significant challenge to standard operative strategies. The concept of eloquent area is evolving and may be potentially extended to all measurable functions. Thanks to collaborative teamwork in neuroscience and neuro-oncology, current neurosurgical innovations aim to improve our anatomical, physiological, and functional understanding of the surgical region of interest with a view to prevent potential morbidity during resection and improve the patient's quality of life (QoL), an essential outcome measure.

\section{Requirements and methodological constraints}

One of the main requirements for brain mapping is to have a valid, repeatable, sensitive tool to stimulate functional areas while administering an appropriate test. Electrical stimulation parameters and tests may be adapted to the individual patient according to several individual variables. This makes the mapping procedure extremely variable and imposes methodological constraints subject to validation in individual cases. The method involves comparing intraoperative against postoperative findings classified as true positive (with or without intervention), true negative, false positive, false negative (Wiedmayer et al., 2004). Task must be easy to perform and robust, capable to impact postoperative clinical state without limiting surgical resection. Clinical feedback is used to validate the overall intraoperative strategy while considering additional outcome parameters suggested by surgical management guidelines: extent of resection; complications; neurological and neuropsychological state; functional state and survival (Chang et al., 2003). Finally, new 
mapping techniques, like fMRI and DT imaging-based tractography (DTI), should be compared with ECS to determine their sensitivity and specificity.

\subsubsection{Patient cooperation and compliance in awake surgery}

Candidates for awake surgery face an unpredictable experience. To date, the choice depends on the patient who will have received a detailed description of the procedure and provided fully informed consent. Although awake craniotomy is generally considered to be well tolerated, complications such as emotional distress and agitation are not uncommon, with loss of control, the need for more sedation and failure of the mapping project. Failure rates due to agitation vary from 2 to $8 \%$ but are not systematically reported (Danks et al., 1998; Sahjipaul, 2000; Whittle et al., 2005).

\subsubsection{Preoperative clinical assessment}

Together with imaging, symptoms and objective findings will guide the surgical strategy. Disturbances in language-related functions, whether transient or progressive, functional or organic, are more indicative of operative risks than the lesion location itself (Benzagmout et al., 2007; Peraud et al.,2004). The standard assessments for dominance are the Edinburgh handness test, the Wada test and/or fMRI with the verb generation task (Duffau et al., 2003a).

The second step in patient assessment is neurological examination. It can reveal motor impairment (Medical Research Council scale, John, 1984) and disturbances in speech and cognition; however, it cannot provide reliable or sufficient information about the type of dysphasia or specific classification nor recognize mild impairments. This is an important drawback, since the rate of patients with mild-moderate deficits undergoing AS for mapping is quite high (26-55\%) (Bello et al., 2007; Sanai et al., 2008; Skirboll et al., 1996).

While there is general consensus that mapping requires that patients present no significant disturbance at intraoperative task testing, some authors have underlined the utility of preoperative assessment, showing how sensitive tasks can maximize testing efficiency. The clinical aim is to recognize preserved functions or subprocesses in order to preserve them intraoperatively (Petrovich Brennan et al., 2007; Pouratian et al., 2003). This research can be pursued through consultation with a group of cognition experts during operative planning to develop personalized tests and tasks for a given patient. Specific functions include: spontaneous speech; language fluency; object naming; written/oral comprehension; reading; dictation; and repetition (baseline for French authors). Added to these are tasks involving writing sentences and words, oral controlled association by phonetic cue and semantic cue, famous face naming, action picture naming, transcoding tasks (Bello et al., 2007; Sanai et al., 2008). Nevertheless, evaluation was limited to the naming task before intraoperative assessment in the majority of cases (Haglund et al., 1994; Hamberger et al., 2005; Ojemann, 1989).

Reviewing the literature, the role of the neuropsychologist in AS is seldom defined in relation to treatment and little attention has been paid to the impact of primary brain tumors on QoL (Buckner et al., 2001; Giovagnoli \& Boiardi, 1994; Taphoorn et al., 1992, 2005; Weitzner et al., 1996; Weitzner \& Meyers, 1997). Differently from other cancer patients, where the burden of the disease is assessed, in brain tumor patients a decrease in cognitive and emotional functioning may be the result of cerebral disease. Subclinical symptoms, personality changes and mood disturbances may prove to be as burdensome to patients, or 
more so, as certain focal neurological deficits (Giovagnoli et al., 2005; Talacchi et al., 2010b). Often, they go unrecognized at self assessment; judgment requires trained experts, like those cited above, with oncological experience (Pahlson et al., 2003; Taphoorn et al., 2004). Tumors in the dominant hemisphere may profoundly affect a patient's cognitive function well beyond language function. Although some deficits are known to be related to tumor localization, in brain tumor patients, especially in those with a LGG, many studies failed to find deficits restricted to a single cognitive domain (Tucha et al., 2000; Yoshi et al., 2008). This makes the assessment test battery crucial for global evaluation and longitudinal study.

\subsubsection{Tasks, functions and circuits}

Ojemann attempted to describe a distribution of language functions (Ojemann, 1989, 2003). He reported that naming interferences occur over a wide area of the left lateral cortex, extending beyond the limits of the classical model. He also found substantial variability in individual organization (Ojemann, 1977; Ojemann \& Mateer , 1979; Ojeman G.A. et al., 1989; Ojeman, S.G., et al., 2003). Commonly, at least one area was described in the inferior frontal gyrus and one or more areas in the temporo-parietal peri-sylvian cortex. Other studies identified naming locations in specific regions such as the insular lobe, the striatum and opercular region, and the basal temporal language area (Duffau \& Fontaine, 2005; Duffau, et al., 2005; Hamberger, et al., 2001; Ilmberger, et al., 2001; Lüders et al, 1988, 1991; Peraud et al 2004). However, even though surgical resection will ordinarily respect positive site margins, patients may still display a postoperative language deficit (Petrovich Brennan et al, 2007).

Single neuron recording provides a very sparse distribution of circuits which can be difficult to study with focal electrical interference (Waydo et al., 2006). Language, whose underlying primary neuronal substrate was termed "module", small areas measuring 1-2 $\mathrm{cm}^{2}$ with well-defined boundaries, represents a fortunate exception to this observation rather than the rule (Ojemann, G.A. et al., 1989). In addition, many authors showed that naming sites are often in close relationship to specific sites for different language functions, verb generation, reading, counting, comprehension, writing, working memory, and calculation, which justify the terminology adopted for designating them (nodes and shell-core) (Haglund et al., 1994; Schwartz et al., 1999; Schäffler et al., 1996).

Accordingly, the characteristics of the underlying neural circuits differ among functions and are not yet well understood anatomically. This differences may influence the mapping modality, recording the neuronal activity that "participates" in a widely distributed function with some regional differences. This is the case of intraoperative ECS in the right hemisphere for mapping spatial functions where "positive sites" could be removed while monitoring the corresponding partial deficit during tumor resection (Bartolomeo et al., 2007; Gharabaghi et al, 2006; Thiebaut de Schotten et al., 2005).

\subsubsection{Item selection}

As a standard procedure, an intraoperative task has to be previously verified on each patient before being performed, and those items chosen that patients were able to name during the preoperative testing phase. Items that patients were unable to name at preoperative assessment are deleted (Hamberger et al., 2005; Ojemann, 1989; Roux et al., $2003 \mathrm{~b}$ ). What is not well specified is the cut-off number of items a patient can misname when included in an AS protocol (Roux et al., 2003a; Lubrano et al., 2004). According to Little et al. (Little, et al., 2004), a preoperative object naming error rate greater than $25 \%$ 
cannot statistically correlate with cortical stimulation and therefore cannot be reliably interpreted as evoked by stimulation.

\subsection{Electrical stimulation}

Stimulation depolarizes a very focal area of the cortex which, in turn, evokes certain responses. For example, the 50-60 Hz Penfield technique has long been used to elicit motor responses, documented through direct visual observation of contralateral tonic limb movements in the beginning and since the late 1990s through motor evoked potentials (MEP) recordings (Cedzich et al., 1996, 1998; Kombos et al., 2001; Neuloh \& Schramm, 2002; Penfield \& Boldrey 1937). Although the mechanism of stimulation effects on language are poorly understood, the principle is based on depolarization of local neurons and passing pathways, inducing local excitation or inhibition, as well as possible diffusion to more distant areas by way of orthodromic or antidromic propagation (Ranck, 1975). With the advent of the bipolar probe and electrocorticography (EcoG) for after-discharge (AD) detection as a measure of electrical spreading, avoidance of local diffusion and more precise mapping have been achieved with an accuracy estimated to be $\sim 5 \mathrm{~mm}$ (Haglund, et al., 1992, 1993).

This diversity among protocols is not trivial because it obviously impacts on the results of stimulation. Therefore, function localization may vary across studies as a result of different stimulation parameters and mapping strategies. Moreover, mapping strategies appear as one of the main variables that may affect the results of stimulation: direct cortical stimulation using the so-called short train technique ( 5 to 7 stimuli, $0.5 \mathrm{~ms}$ duration, ISI 4.0 $\mathrm{ms}=250 \mathrm{~Hz}$, with a train repetition rate of 1 or $2 \mathrm{~Hz}$ ) or the $50-60 \mathrm{~Hz}$ Penfield technique (Penfield \& Boldrey, 1937); maximizing stimulation currents at each cortical site to ensure the absence of eloquent function according to AD threshold or keeping stimulation intensity constant, while mapping the entire cortex and setting the threshold just below the lowest current observed to induce AD; monopolar or bipolar stimulators; stimulation parameters in subcortical white matter according to cortical response or at the lowest threshold to evoke a response, all these alternatives may be encountered in similar studies.

\subsection{Positive sites}

Ojemann, using the single sample binomial test to check whether a site is essential for language, examined the accuracy of response during naming (Ojmann \& Mateer, 1979; Ojeman, 1989). He gave a nonparametric description to determine if a site can be interpreted as essential: " a site was determined to be related to language function if the chance probability of errors evoked at that site was less than 0.05 [...] evoking errors during two of three stimulations at a site often achieved that level of statistical significance...". This rate was slightly different in others author's strategies (Hamberger, et al., 2005; Peraud, et al., 2004).

The visual object naming task is easy to apply but is much more difficult to interpret. When classifying the type of errors, the main distinction that needs to be made is between speech arrest, anomia and speech disturbances. Error classification is strongly related to the aim of a study; it can vary from a simple definition of error (every change that occurs during stimulation) to a more articulate definition (Bello et al, 2007; Benzagmout et al, 2007; Duffau et al, 1999, 2003b; Duffau, 2006a).

\subsection{The role of imaging in the integrated surgical strategy}

Because of the infiltrating nature of gliomas, it is more than likely that a portion of the mass will occupy or be continuous with functional tissue. However, some evidence 
supports the concept that resection should ideally go beyond the gross tumor margin apparent on preoperative imaging. Therefore, it is not only patients with tumors located within the frontal operculum who may benefit from intraoperative language mapping, but also those with lesions in proximity to this region because of the significant variability in this region's anatomical and functional organization (Edeling et al., 1989; QuiñonesHinojosa et al., 2003).

Possible causes of damage are: trajectory in subcortical tumors; abnormal anatomy in recurrent tumors; distorted anatomy due to the tumor; tumor infiltrating the functioning brain in LGGs; irregular tumors; and tumor periphery in HGGs. All are known to be crucial factors for surgical outcome, and knowledge of the structural characteristics of eloquent areas may help the surgeon to avoid clinical consequences. Aims may be categorized as linked to: 1) orientation, which is usually not histology-dependent (trajectory, abnormal anatomy, distorted anatomy); and 2) removal, usually used for specific gliomas (low-grade, irregular margins, periphery).

\subsubsection{Functional imaging for eloquent tissue localization}

Considerable advances in functional imaging have been made in both technology and availability, raising the question of whether it may eventually supplant intraoperative ECS mapping. Devices such as fMRI and PET units may aid in the preoperative planning of resection strategy, but these techniques, while reliable for detecting the motor area, remain too imprecise for complex functions such as language mapping where their sensitivity (PET, 75\%; fMRI, 81\%) and specificity (PET, 81\%; fMI, 53\%) are suboptimal. (Fitgerald et al., 1997; Herolz et al., 1996, 1997). These modalities highlight language-associated areas of indeterminate significance, and they do not offer real-time information intraoperatively. To this end, MRI neuronavigational techniques can facilitate not only greater resection, but embedding of DTI can also prevent inadvertent resection of adjacent subcortical pathways (Talos et al., 2007; Wu et al., 2007). Although the use of DTI has not been shown to impact directly on patient survival, its utility resides in maximizing tumor resection while minimizing morbidity. Nevertheless, for the identification of functional language pathways and guidance of safe tumor removal, these diagnostic imaging tools remain supplements to, not substitutes for, direct intraoperative stimulation mapping.

\subsubsection{Structural imaging for tumor periphery localization}

In glioma surgery, the approach to subcortical diffuse gliomas and the decision to resect the infiltrated brain surrounding the tumor core are the cornerstones of modern, aggressive surgical strategy. This is the rationale for a sound command of knowledge of brain functions at the tumor margin in individual cases. Non-enhancing tumor periphery, pattern (sharp or blurred) and characteristics (edema or infiltrated brain) constitute the challenging part of the operation where most effort is concentrated. MRI, FLAIR and T2weighted images will visualize structural properties but their priority is controversial. Spectroscopy and DTI have been advocated as promising tools for delineating the extent of tumor infiltration (Price, et al., 2003; Stadbauer, et al., 2004, 2006). In addition, anisotropy measures have attempted to differentiate edema from infiltrated brain ( $\mathrm{Lu}$, et al., 2003, 2004). In contrast, perfusion can help to distinguish tumor grading but has not given information about the periphery so far. 


\section{Intraoperative setting}

AS is a challenge for a working team, since it implies substantial modifications in the professional behavior of all physicians involved: for the surgeon working in an uncomfortable situation; the anesthesiologist monitoring the patient continuously; the neuroradiologist awaiting intraoperative confirmation of interpretation of findings; the neuropsychologist making real-time evaluation of scans. AS involves a complex scenario: integration of different types of knowledge, organization of a heterogeneous team, cooperation in different settings (operating room, ward, out-patient clinic), surgical and research protocols to be adopted, technical adjustments to make the research comparable.

\subsection{Anesthesiology}

Awake surgery is performed as follows. Continuous sedation (Sarang, et al.,2003) was achieved with rapidly acting agents and infiltrative anaesthesia of the scalp. Airway management remains a concern due to the risk of aspiration or oversedation with oxygen saturation $<90 \%$. Patients breathe spontaneously during awake surgery. Propofol, fentanyl, remifentanyl and midazolam are commonly used agents. Volatile anaesthetics should not be given because they interfere with electroencephalographic (EEG) recording and cause a dose-dependent distortion on the EEG, with vasodilatation resulting in increased intracranial pressure (ICP) (Himmelseher, et al., 2001). While propofol can also alter the EEG (Herrick, et al., 1997), intravenous drugs are preferable because of their rapid onset and easily manageable duration of action which causes no nausea or vomiting. The sedation level is very important since oversedation results in an uncooperative patient and medical problems (i.e., respiratory depression), whereas undersedation makes the patient uncomfortable and restless. For this purpose, the Modified Observer's Assessment of Alertness/Sedation Scale (Bauerle, et al., 2004) was used.

The feasibility and efficacy of AS have been studied in comparison with general anesthesia (GA). The absolute anesthesiologic exclusion criteria for AS are obstructive sleep apnea and difficult intubation (Picht et al., 2006). Parameters for comparing GA versus AS:

- Duration of surgery: according to Gupta, the mean procedure time was shorter in the GA group than in the AS group (182 min vs. 196 min; p <0,05) (Gupta, et al., 2007). A similar duration was found by Keifer and Taylor (Keifer et al., 2005; Taylor \& Bernstein, 1999). Bello reported longer durations: mean 5 h 45 min, longest 6 h 45 min; mean awake time $1 \mathrm{~h} 45 \mathrm{~min}$ (Bello et al., 2007). In Whittle the mean awake duration was 62 min (range 10-105 min) (Whittle et al., 2005).

- Intraoperative medical complications are classified as anesthetic (inadequate or excessive sedation, pain, nausea, vomiting); respiratory (oxygen saturation $<90 \%$, increased CO2, hypoventilation $<8 / \mathrm{min}$, airway obstruction); hemodynamic (hyper- o hypotension, tachy- or bradycardia); neurological (convulsions, brain swelling, new neurological deficit) (Costello et al., 2005; Keifer et al., 2005; Sarang, \& Dinsmore, 2003). In a review of the literature, Skucas demonstrated how hyper- and hypotension could be frequent in AS (11 and 56\%, respectively) (Skucas, et al., 2006). However, in their study on 332 patients, they observed that airway problems are not so frequent: only $2 \%$ of patients developed hypoxemia and only $1.8 \%$ required intubation or positioning of respiratory devices. Respiratory issues could arise more frequently in obese patients or those with asthma or chronic obstructive pulmonary disease (COPD). As concerns intractable seizures in unconscious patients, the study reported that seizures occurred in only $3 \%$ 
of patients, whereas other studies have reported rates as high as 16\% (Bello et al., 2007; Petrovich Brennan et al., 2007; Serletis et al., 2007; Taylor \& Bernstein, 1999). Some authors advocated the use of propofol to reduce intraoperative seizures (Berkenstadt et al., 2001; Danks et al., 1998; Gignac et al., 1993; Herrick et al., 1997; Huncke et al., 1998; Sarang, \& Dinsmore, 2003).

- Blood loss: Gupta observed that blood loss is less in AS than in GA (266 ml vs. $365 \mathrm{ml}$; $\mathrm{p}<0.05)$ (Gupta et al., 2007).

- Postoperative local complications: Taylor found a $2.5 \%$ wound-complication and postoperative hematoma rate, similar to that described in a large study conducted on 1427 elective supratentorial craniotomies (Taylor et al., 1995; Taylor \& Bernstein, 1999).

- Mean postoperative hospital stay and intensive care unit (ICU) stay: these are not significant results (Gupta et al., 2007). An awake craniotomy carries low morbidity and mortality rates and minimizes the need for ICU admission and the total hospital stay.

- Patient age: most authors agree that patients must be older than 11 years (Berger et al., 1989).

\subsection{Clinical and imaging recording}

Patient response during awake mapping is an important component in the data analysis also after surgery. Published data show different levels of analysis of response depending on the aim of mapping. Specifically, response registrations depend upon the presence of a either professional figure in the operating room for providing a written record of the findings or the use of audiotape or/and videotape recordings to be evaluated by a blinded or multiple postoperative examiners (Corina et al, 2005; Duffau et al., 2006; Haglund 1994; Sanai et al., 2008).

Audio-videotaping the mapping procedures is particularly useful for checking mouth and face muscles in order to classify language disorders and to detect eye movements which, mostly in frontal sites, could interfere with reading (Malow et al., 1996; Milea et al., 2002; Peraud et al., 2004; Roux et al., 2003b; Van Buren \& Fedio, 1978). Documentation with pictures or audio-videotape of the brain was systematically obtained during stimulation to match sites with response site by site.

\subsection{Positioning}

Positioning is a compromise between patient and surgeon comfort. Ideally, positioning attains a head position that should fulfill requisites besides those of the surgeon: patient muscle relaxation; airways accessibility for the anesthesiologist; and the possibility of talking and interacting with the staff including watching the personal computer. For these reasons, the patient is positioned while awake. A rigid headrest with pins is perfectly tolerated by the patient after the administration of a local anesthetic.

\subsection{Craniotomy}

Language-mapping techniques were historically developed in the context of epilepsy surgery, in which large craniotomies exposed the brain well beyond the region of surgical interest to localize multiple cortical regions containing stimulation-induced language and motor function (i.e., "positive" sites) prior to resection. Recently, with increasing reliance on mapping, craniotomies have gradually been reduced to the size necessary to approach the lesion, thereby allowing for minimal cortical exposure overlying the tumor, less extensive 
intraoperative mapping, and a more time-efficient neurosurgical procedure (Sanai et al., 2008).

\subsection{Surgical instruments}

Essential devices for accurate surgical techniques are the intraoperative microscope and the ultrasonic aspirator. The neuronavigator has a multipurpose application: define the cortical boundaries of lesions, especially in LGGs; establish the site of corticectomy and the trajectory to subcortical lesions; provide image-assisted surgery for both fMRI (motor task) and DTI; and establish the distance to anatomical landmarks. These advantages are limited to the first part of the operation prior to brain shift. In this regard, intraoperative MRI is a promising tool for improving accuracy in subcortical mapping of fascicles and functions.

\section{Surgical resection strategy}

The intraoperative mapping technique involves selecting the tasks in relation to preoperative assessment, the operative tools, the neurophysiologic parameters and the consequent strategy, i.e., the way we combine them in a clinical situation. Taken together, these costly and time consuming procedures point to the importance of methods and surgical strategy.

One substantial limitation to clinical comparative inference is that multiple cortical or subcortical sites are manipulated during an operation making it impossible to relate one event to the manipulation of one site. In other words, when forced to face a number of methodological issues, it is likely that surgical strategy will improve. Choices regarding positioning, surgical technique, tumor definition, clinical and intraoperative information, functional studies, intraoperative tools, all together will favor a good result. In contrast, consideration of only one or a few functional variables may be confounding. This is why research studies should be validated in the clinical setting, taking into account additional variables critical for this purpose (Sawaya et al., 1998). Furthermore, the challenge of AS and cognitive mapping is the working team, i.e., to what extent individual proficiency can contribute to a clinical purpose when working in a group.

\subsection{The traditional approach (Yasargil's lesson)}

Yasargil lesson's may be summarized as follows: 1) glioma is an infiltrative tumor only in its advanced stages of growth; 2) its growth pattern follows functional pathways and respects compartmental boundaries (neo-archipallial, central nuclei, white matter and ventricles); and 3) tumor debulking starts from the center and proceeds in a circumferential manner till the white matter is exposed ("the deflating ball and one window" techniques) (Yasargil, 1996b, 1996c; Yasargil et al., 2004).

This last point is justified by the risk of damage to adjacent brain areas and forms the basic principle of resection strategy. In light of recent pathological and functional knowledge, however, this defensive strategy for treating both LGGs and HGGs, which seeks foremost to avoid brain injury without considering the infiltrated brain or the functional characteristics of adjacent brain areas, now seems largely unwarranted. Nonetheless, it is not an absolutely safe technique, since HGGs are often highly vascularized tumors and bleeding may mask vascular or parenchymal structures and result in involuntary injury. Moreover, tumor manipulation may induce tissue swelling and physical modifications, altering the typical 
characteristics of the normal brain, thus confounding the neurosurgeon's judgment, which basically relies on visual inspection.

The simple observation that, as a rule, recurrences originate from the margins of the operative cavity should underline that additional resection is a primary aim of surgery if it does not endanger functions that could impair patient performance, the accurate knowledge of which was the limiting factor of the strategy. Bearing this in mind, the rationale of the current approach becomes readily understandable: attack the tumor at its margins.

\subsection{The current approach according to mapping information}

As a preliminary consideration, the knowledge how a tumor grows may orientate the cortical approach. As the glioma grows in the gyrus, it infiltrates the short tracts (the $u$ fibers) first and then the longer tracts, rather than the pia. Consequently, a direct or sulcal approach will be unsuitable for diffuse tumors in which resection of the involved gyrus and eventually the adjacent gyrus is preferable (Meyer et al., 2001). Corticectomy at this site, at the tumor margin, is the main surgical innovation of brain mapping. Cortical mapping highlights positive and negative areas before starting resection. This "negative mapping" strategy represents a paradigm shift in language and no-language mapping techniques by eliminating the neurosurgeon's reliance on positive site control in operative exposure, although validation for other related functions is still needed (Berger, 1994; Black et al, 1987; Keles \& Berger, 2004; Matz et al., 1999; Sawaya et al., 1999; Toms et al., 1999).

Cortical LGGs may be nearly indistinguishable from normal brain tissue. The neuronavigator is therefore essential for precisely demarcating the superficial limits of the tumor. The arachnoid opening is also useful before deciding on the area of resection. The exact distinction acquired with the neuronavigation system may provide immediate visual feedback during the initial subcortical resection when the resection proceeds between different tissues.

The technique is to start from safe areas and where the vascular supply is expected: following the vessels, skeletonizing and preserving those serving eloquent areas and dividing the others, especially those supplying the tumor, in order to devascularize it. Subcortical pathways perpendicular to positive sites can be followed within the infiltrated brain as far as apparent normal brain is exposed or positive mapping is detected. This is not always possible in language areas, since the closer we come to positive sites, the easier it will be to have intraoperative impairment which will prevent further mapping. Consequently, in language mapping, DTI may be of help in orientating where to map on the tumor periphery in order to stimulate the least possible. DTI may be not considered as more than a imaginary guide.

This strategy may be changed in some situations, for instance, with less cooperative patients and during long operations, by adopting the following sequence: mapping, starting resection close to positive sites and following subcortical pathways, and then approach the vascular supply and safe areas. Repeating the mapping subcortically 2-3 times is usually enough, even when anatomical distortion occurs.

Starting from safe areas enables us to follow the tumor into the transition zone, from the margins to the infiltrated brain till the normal brain. First sight inspection means starting resection from the tumor periphery before causing possible injury, which can alter tissue color. Here, the microscope is essential for magnifying the region in order to differentiate normal brain from infiltrated brain. This major challenge can be successfully addressed only by experienced neurosurgeons. The corridor measures about $1 \mathrm{~cm}$ taken mostly from the 
infiltrated brain and less from the tumor. Since diffuse tumors are heterogeneous, it's better to see the phenotype of the single variant from the beginning and possibly to stay around the tumor, creating a corridor between the infiltrated brain and the normal brain. Starting from the corridor created around the tumor, additional space is obtained by removing or retracting the tumor and leaving the brain untouched. The rule is: expose the normal brain, map and stay away from it. Working very closely to normal brain tissue implies avoiding any pressure and retraction that could cause brain injury. As a rule, use of the self-retaining spatula is unnecessary and dangerous. This strategy provides us with a better anatomical orientation in a context which is still similar to the anatomo-functional picture as acquired preoperatively with MRI.

Following large, randomized prospective studies in Europe, several countries have already approved, and are now using, 5-ALA for improved quality of resection in HGGs, aimed at assisting the surgeon according to the same resection strategy (Stummer et al., 2006).

The standard for subcortical mapping for language is not yet defined: current amplitude, functional significance of fasciculi, safe distance from fasciculi or tolerance of partial injury, tests to be used, false negative stimulation rate, definition of positive sites, method of validation of positive sites. In particular, continuous monitoring is affected by the learning effect, as described by Ojemann ( Ojemann J.G., et al., 2002).

The limiting factor to total removal is not always the eloquent areas. In large and diffuse tumors we can state that a strategy aimed at exploring and removing safe areas first is a preliminary condition to continue this aggressive strategy in order to obtain maximal resection which justifies risks in eloquent areas. Safe exposure of deep structures is not always feasible; and facing increasing structural and functional uncertainties is preferable to stopping the operation before taking additional risks in eloquent areas, assuming that the degree of cytoreduction has limited value if total removal cannot be achieved (Lacroix et al., 2001).

Vascular injury may be another limiting factor to tumor removal, especially in insular tumors where transit and terminal arteries, normal and pathological arteries, and venous drainage are ever-present challenges during the operation.

\subsubsection{Temporo-insular tumors}

The approach to temporal and insular tumors may be trans-cortical or trans-sylvian. When corticectomy is done, the tumor is devascularized by subpial dissection, while trans-sylvian dissection makes it possible to follow the vessels, free the tumor, and then decide which vessels to preserve and which to divide. The lenticulostriate arteries, the parietal trunk of the middle cerebral artery bifurcation on the non-dominant hemisphere and both trunks in the dominant hemisphere and the long perforators running posteriorly are the critical vessels to preserve in order to avoid permanent language and motor deficits. As a rule, vessels smaller than $0.5 \mathrm{~mm}$ are pathological. In these tumors, temporal or frontal basal cortical areas are seldom the critical point of resection, and multiple windows can be created between vessels. Accordingly, various sequential options may be weighed in order to start from safe areas and to control arterial vessels (Duffau, 2009; Sanai et al., 2010, Simon et al., 2009).

Mapping techniques allow the neurosurgeon to recognize the internal capsule, which is the critical anatomical point, at least in a non dominant site, while additional information can be obtained from monitoring motor evoked potentials (MEPs) in the course of the operation since insular tumors carry a risk of vascular injury, higher than the risk of direct injury (Figure 1-3). Neuloh and Schramm highlight the semi-quantitative relation between MEP 


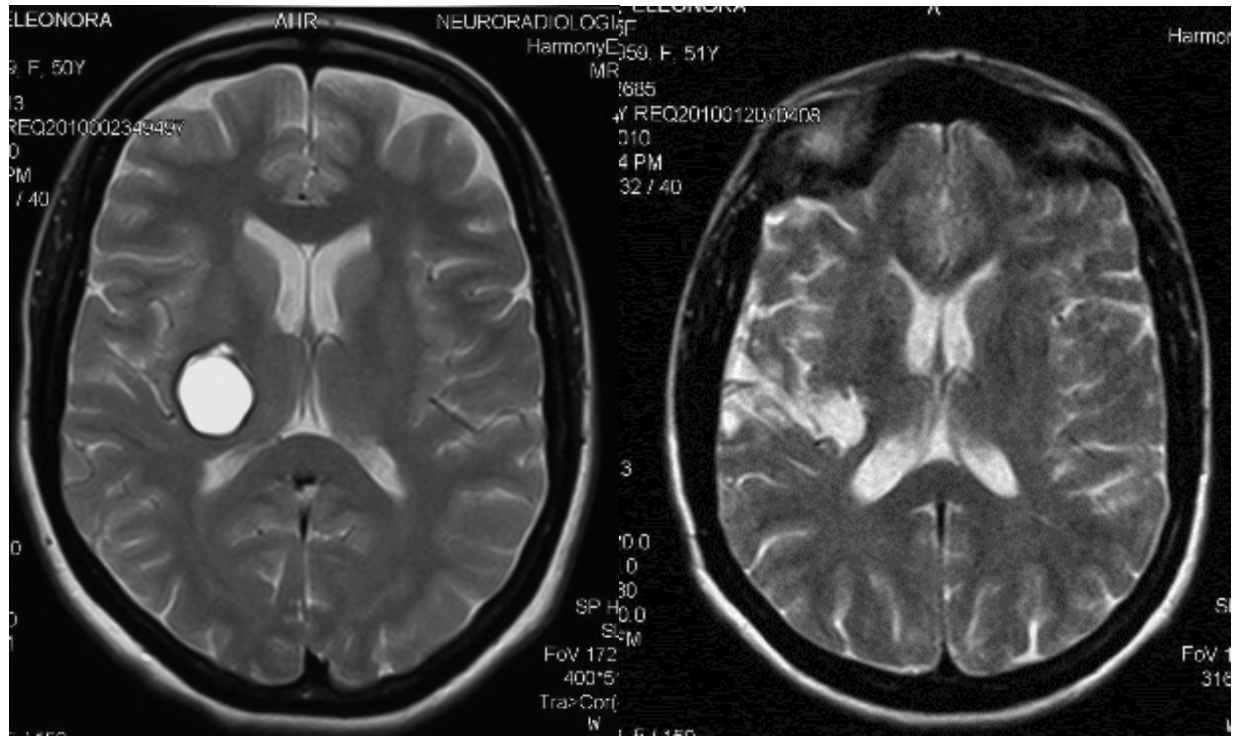

Fig. 1. Pilocytic astrocytoma of the right posterior insula. The tumor was removed via a trans-sylvian approach assisted by intraoperative motor monitoring (preoperative on the left side; postoperative on the right side)

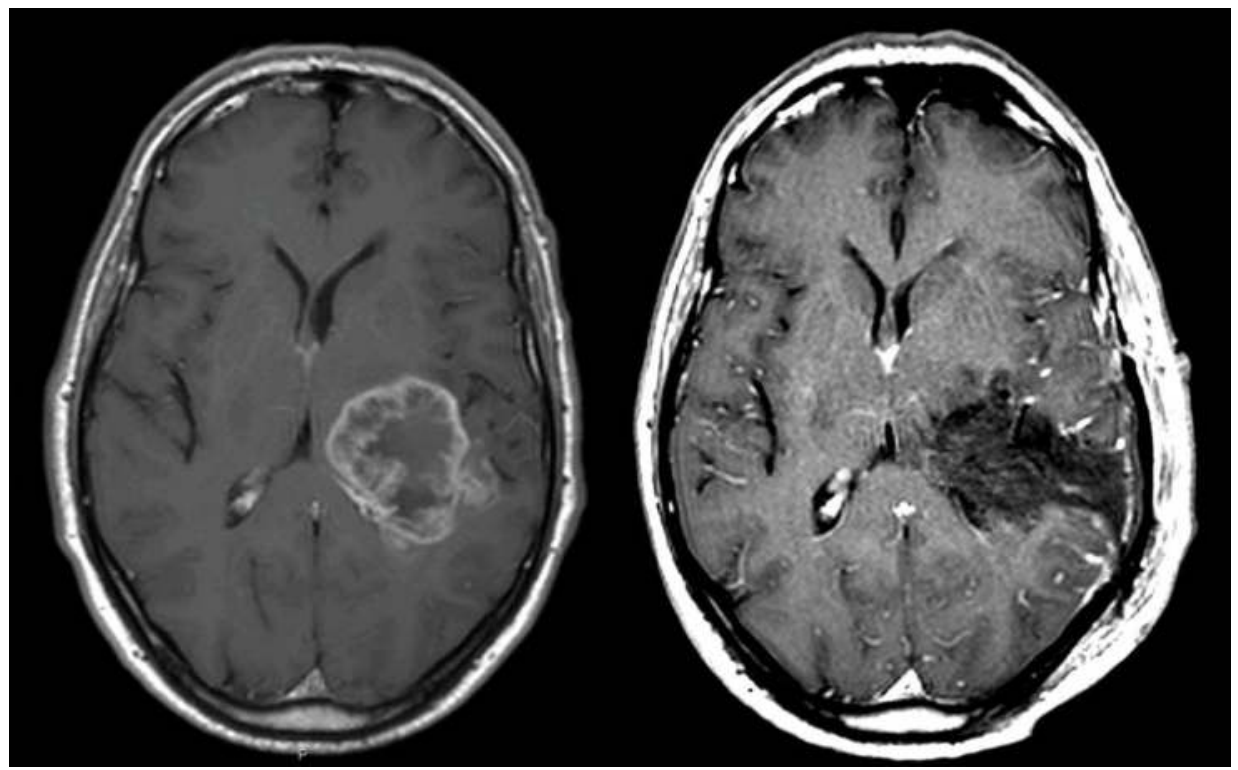

Fig. 2. Left posterior temporo-insular glioblastoma. The tumor was operated on under awake surgery for cortical language mapping and subcortical motor monitoring. Posterior perisylvian cortical sub-cortical approach was used for tumor removal (preoperative on the left side; postoperative on the right side) 

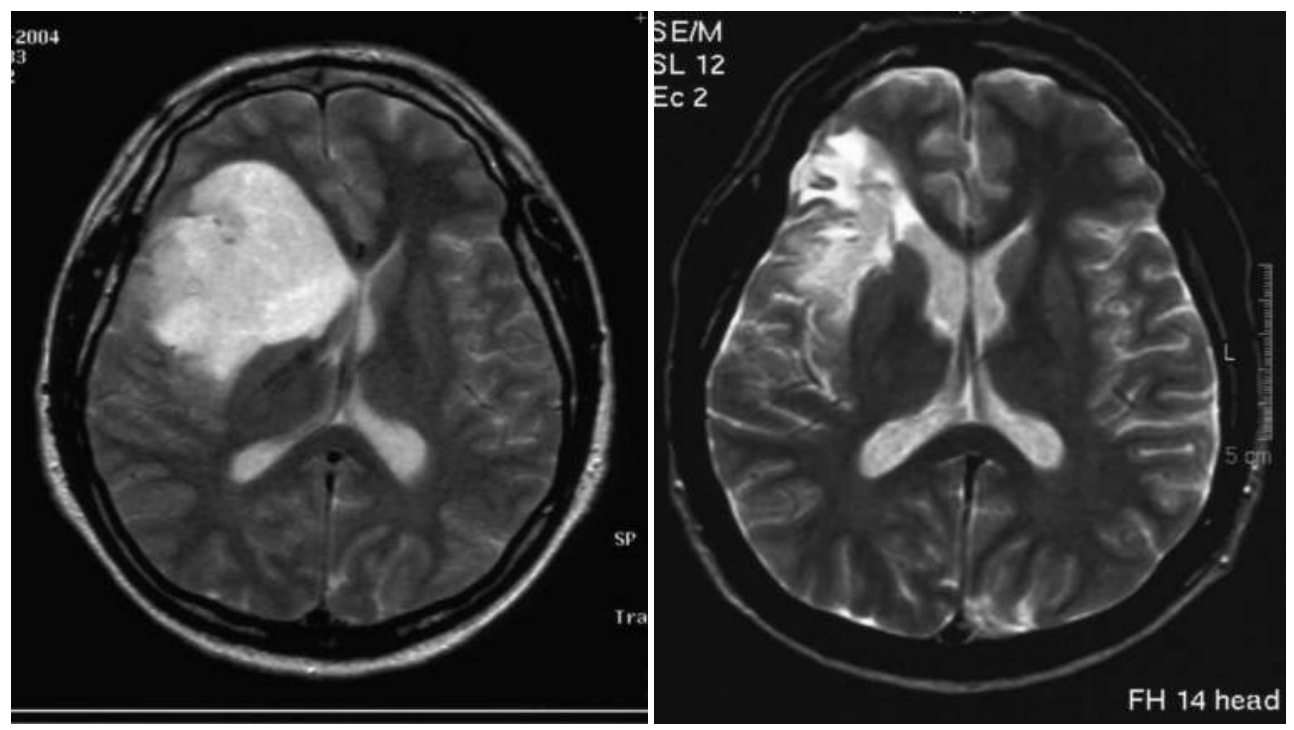

Fig. 3. Right insular fibrillary astrocitoma. Trans-sylvian approach was used and tumor removal was achieved under motor monitoring (preoperative on the left side, postoperative on the right side).

findings and clinical outcome. An amplitude reduction between 25 and 50\% increases probability of a postoperative permanent deficit, as well as reversible loss and irreversible loss of MEPs (Neluoh \& Schramm, 2004). Typically, MEPs deterioration will allow the neurosurgeon or anesthesiologist to react promptly, with temporary or definitive discontinuation of resection in the critical target area, readjustment or temporary release of retractors if used, application of papaverine to spastic vessels and increased blood pressure.

\subsubsection{Rolandic tumors}

The well-known corticospinal tract may be difficult to identify in pathological situations where brain distortion alters the normal anatomy. This is the main concern in the surgical approach to fronto-parietal tumors, the supplementary motor area (SMA) being secondary in importance. Image- and neurophysiologic-assisted surgery may be effective as well (Talacchi et al., 2010a). Vascular supply derives from the distal branch of the pericallosal artery and the fronto-parietal distal branches of the middle cerebral artery. Phase reversal, MEPs, cortical and subcortical mapping allow identification of the central sulcus, motor area and descendent pathways, respectively. The closest safe and convenient distance is $5 \mathrm{~mA}$ for diffuse tumors and 1-2 mA for circumscribed lesions. This is the site with the best surgical results among eloquent areas (Talacchi et al., 2010a) (Figure 4).

\subsubsection{Peri-sylvian dominant tumors}

In this area the great advantage of intraoperative mapping was to render tumors operable which were otherwise not amenable to surgery because of an unpredictable risk of aphasia. The language-mapping technique described in detail by Ojemann remains the mainstay of this procedure and may be combined with motor mapping in the fronto-parietal area, for both the periphery in cortical tumors and for trajectory planning in subcortical tumors 
(Ojemann G.A. et al., 1989). Methodological validation for subcortical language mapping is still lacking, and landmarks for presumed significant fascicles are not well defined and often altered by anatomical distortion. In awake patients, there is an approximately $10 \%$ risk of finding a positive site within the tumor, which remains the main limiting factor to removal (Ojemann G.A. et al.,1989) (Figure 5-6).

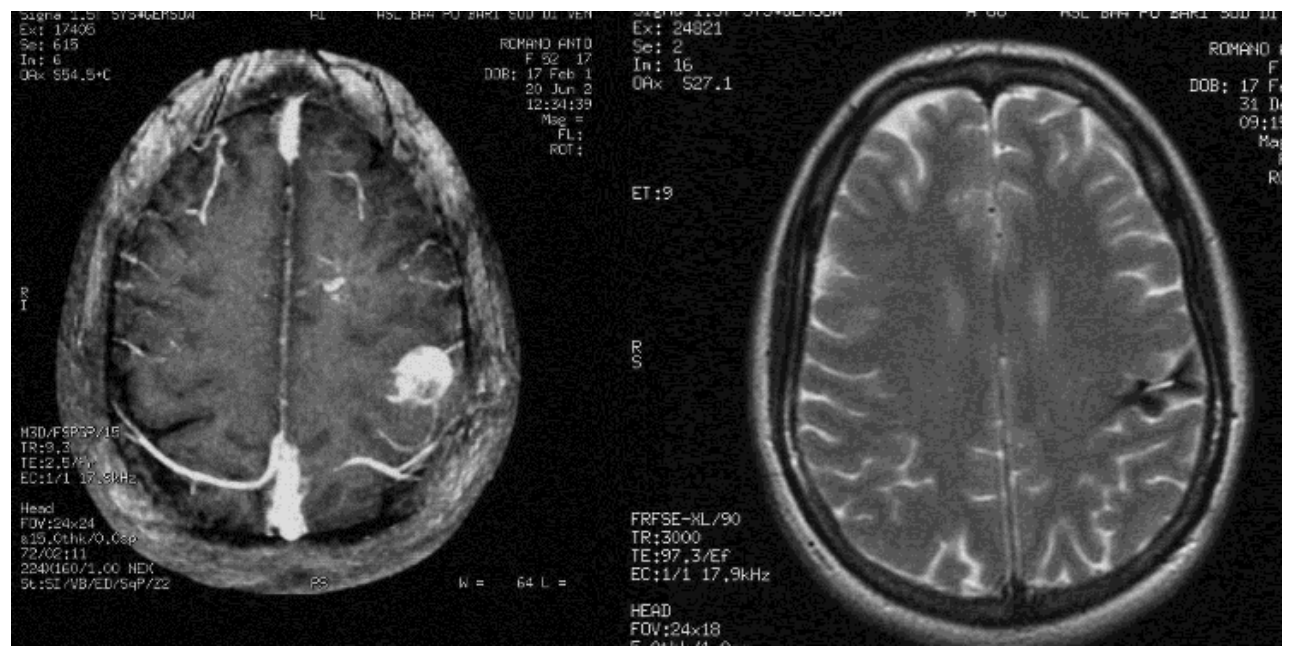

Fig. 4. Left rolandic glioblastoma. The tumor was removed using motor monitoring (preoperative on the left side; postoperative on the right side).

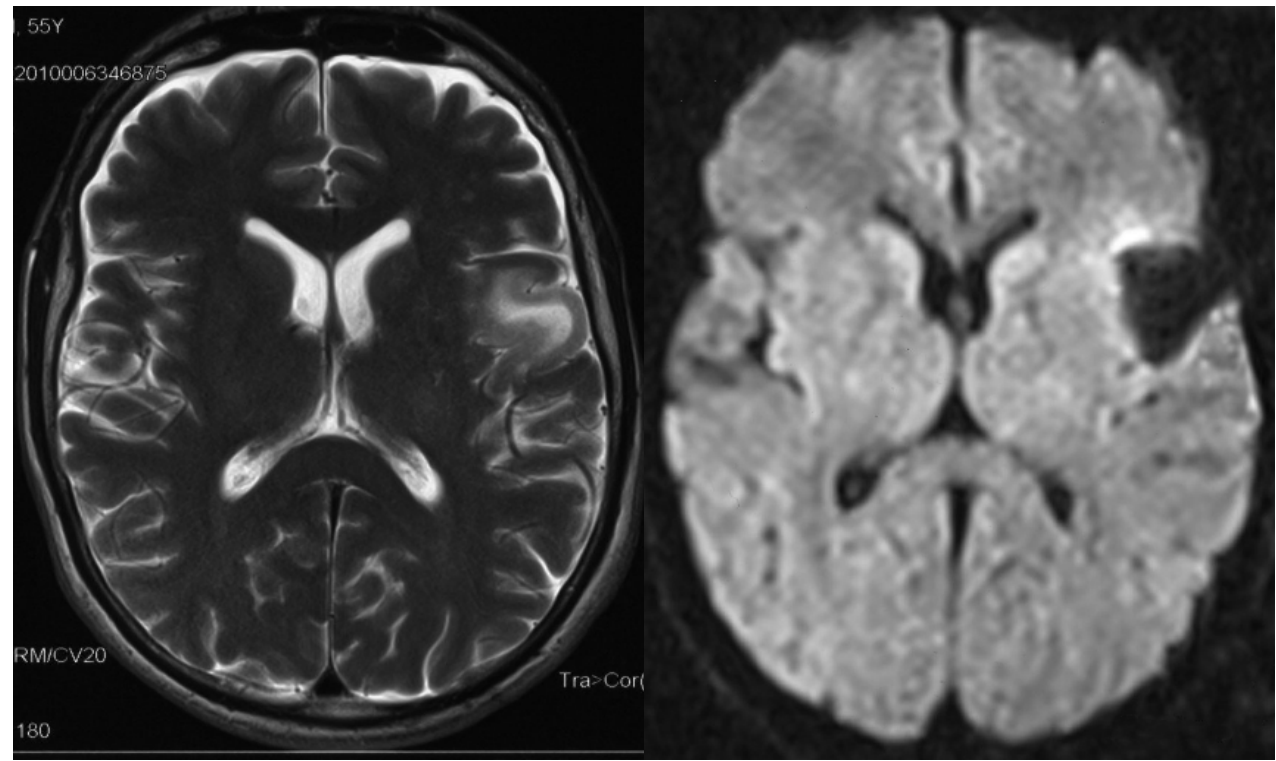

Fig. 5. Left frontal oligodendroglioma in the Broca area. The tumor was removed under awake surgery (preoperative on the left side; postoperative on the right side). 


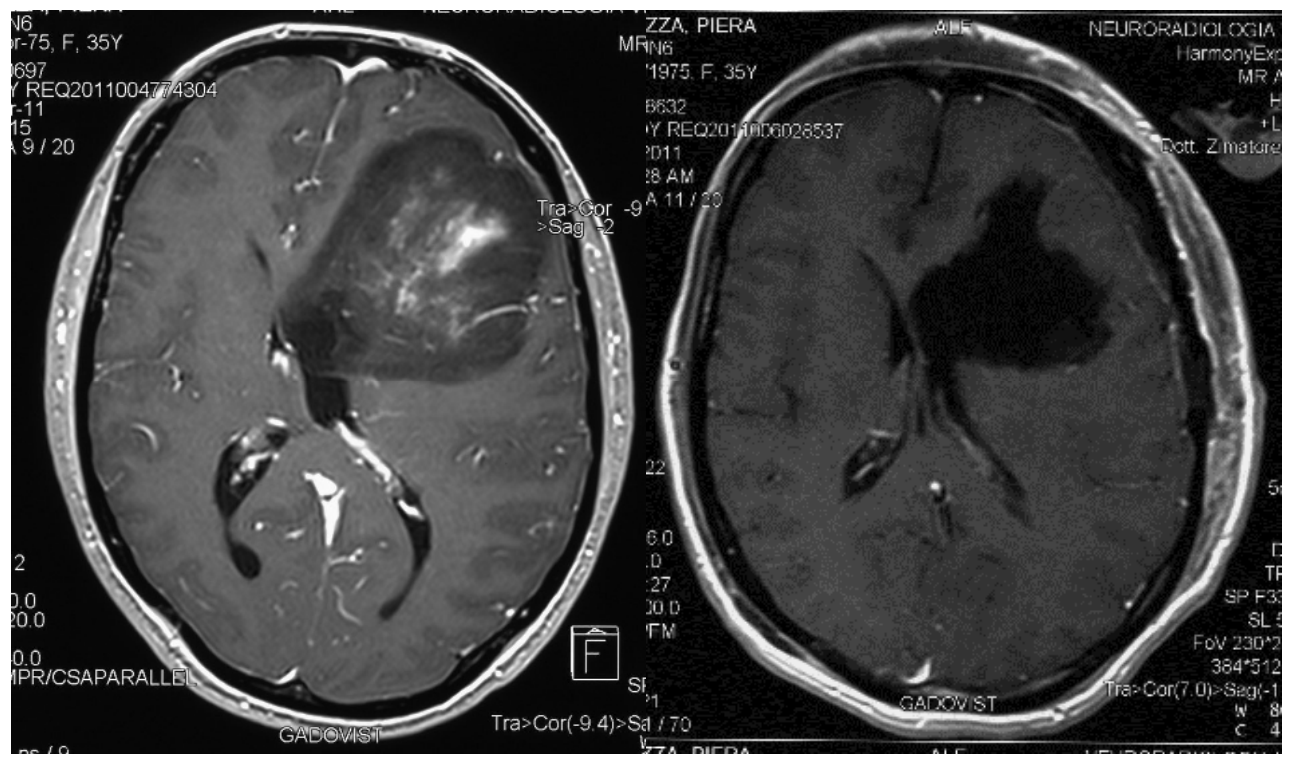

Fig. 6. Huge left frontal oligodendroglioma with intraventricular invasion. Notwithstanding intracranial hypertension awake surgery was used in order to perform a safe perisylvian trans-cortical approach (preoperative on the left side; postoperative on the right side).

\section{Outcome assessment}

While the initial assumption was that no electrically identified areas should be removed if postsurgical language complications are to be avoided, it was later increasingly assumed that postsurgical language deficits would not occur only if cortex that did not result in language deficits with electrical stimulation was removed (Sanai et al., 2008). This indirect message is gaining strength, although most studies lack pre- and postoperative global assessment and objective determination of cognitive complications. Furthermore, the original assumption that resection of any essential language areas will result in postoperative aphasia has not yet been definitively confirmed nor has the assumption that sparing positive sites for naming task will result in sparing of other language functions (Hamberger, et al., 2005; (Peraud, et al., 2004; Petrovich Brennan, et al., 2007; Seek, et al., 2006; Whittle, et al., 2003, 2005).

Moving from intraoperative naming-assisted surgical resection to other language and cognitive tasks, before relying on new protocols we need a multi-staged system of evidence for the potential and limitations of AS for cognitive mapping, its clinical validity for a single task or battery of tasks and technical standardization (intentionally addressed in the present article). Meanwhile, patient safety must be guaranteed by accurate comparative assessment, which should be discussed and defined (Lacroix et al., 2001; Vives \& Piepmeier, 1999).

\subsection{The value of glioma extent of resection}

Microsurgical resection remains a critical therapeutic modality for all gliomas (Black, 1998; Guthrie \& Laws, 1990; Keles et al., 1999; Yasargil et al., 2004). For all gliomas, the 
identification of universally applicable prognostic factors and treatment options remains a great challenge. Among the many tumor- and treatment-related parameters, only patient age and tumor histological characteristics have been identified as reliable predictors of patient prognosis, although tumor location in an eloquent area and the patient's functional status can also be statistically significant. With significant advances in brain tumor imaging and intraoperative technology during the last 15 years, some reports showed that improved extent of resection has a significant effect on both tumor progression and overall survival (Bauman et al., 1999; McGirt et al., 2008; Sanai et al., 2010; Smith et al., 2008). Although LGGs and HGGs are distinct in their biology, clinical behavior and outcome, understanding the efficacy of surgery remains equally important for both.

As concerns longer overall survival, more aggressive resection for LGGs can also influence the risk of malignant transformation, raising the possibility that surgical intervention can alter the natural history of the disease (Sanai \& Berger, 2008). These associations are evident not only in the patient population with hemispheric LGGs but also in those with specific LGGs limited to specific eloquent subregions such as insular LGGs (Chaichana et al., 2010; Sanai et al., 2010; Simon et al., 2009; Smith et al., 2008).

\subsection{Clinical outcome}

The assumption is that every attempt should be made to preserve neurological functions in order to maintain the preoperative QoL, which is the main clinical outcome. However, postoperative settings vary greatly, often including focal evaluation for the related eloquent area but rarely accounting for complications or a wider battery of cognitive evaluations. Inadequate preoperative assessment can limit postoperative assessment and may lead to overlooking some functions which, though not tested intraoperatively, may still hold prognostic importance.

Interestingly, the peri-operative period, which traditionally lasts for 30 days after surgery, was prolonged in some studies to 3-4 months or up to 12 months, a period conventionally used to define permanent deficits (Duffau et al., 2001; Duffau et al., 2003b; Seitz et al., 1995).

\subsubsection{Surgical outcome}

The rationale for any treatment is bring about benefit superior to the natural history of the disease and to other treatments. The primary aim is to improve neurological outcome by relieving mass effect on normal brain structures without causing damage. Here, the Glioma Outcome Project deserves mention because it classified postoperative outcome and prospectively provided data for a large number of cases, Class II data, a benchmark for future studies. In this study, the majority of the patients improved $(53 \%)$, while neurological, regional and systemic complications accounted for $8.1 \%, 10 \%$ and $9.2 \%$, respectively, as observed at 21 days postoperatively. Unfortunately, eloquent areas were not specifically classified (Chang et al., 2003).

\subsubsection{Focal outcome}

While AS is claimed to decrease postoperative morbidity in eloquent areas, immediate postoperative evaluation showed a high rate of worsening of these functions, usually above $50 \%$, which can be explained by the surgeon's confidence when working with eloquent areas, as demonstrated by progressive improvement within a few weeks (Keles et al., 2004; Talacchi et al., 2010a). At 3 months, this percentage usually decreases to less than $20 \%$ and 
then to $2-10 \%$ over the next months (Bello et al., 2008; Duffau 2005; Nariai et al., 2005). The degree of worsening varies substantially depending on the clinical scale used, arbitrarily classified at one level, with a high and low cut-off, which means great differences in deficits, at two levels (mild, moderate-severe) or at three levels (mild, moderate, severe) (Duffau, 2005; Hamberger, 2007; Nariai et al 2005; Seeck et al., 2006; Simos et al., 1999). A few authors used preoperative specific test categories for postoperative evaluation, site by site (Bello et al., 2008; Lucas et al., 2004; Lubrano et al., 2004). Nevertheless, when objective evaluations were adopted, as for motor mapping, the trend was very similar, with lower rates $(20 \%)$, probably due more reliable testing (Talacchi et al 2010a; Reithmeier et al., 2003; Signorelli et al., 2001).

\subsubsection{Functional outcome}

Postoperative changes in cognitive functioning depend partly on the patient's level of preoperative abilities, especially in impaired patients (Gupta et al., 2007; Ojemann, 1979, 1983; Ojeman G.A. \& Mateer, 1979). This makes the assessment strategy crucial from the beginning, since it can limit interpretations of final results (Hamberger et al., 2003).

Preoperative cognitive assessment is a neglected issue, but of great significance since about $80 \%$ of patients present with some degree of impairment (Talacchi et al., 2010b; Tucha et al., 2000). On the other hand, with pre- and intraoperative cognitive assessment, an extended postoperative assessment, including language and other cognitive functions, is required since research is based on the verification of the initial hypothesis and on unexpected results as well as on safety (Vives \& Piepmeier, 1999).

Some authors found poor agreement when comparing neuropsychological tests with neurological examination and self-assess, especially in cognition, properly expressed only by neuropsychological testing (Pahlson, et al., 2003). Mental problems proved to have a greater impact on QoL than physical problems, which are specifically expressed by KPS, demonstrating that neuropsychology is a sensitive tool for analyzing brain performance, rather than self-assessment and neurological examination (Giovagnoli et al., 2004; Gustafsson et al., 2006; Påhlson et al., 2003; Taphoorn et al., 1992). In addition, specific cognitive domains such as verbal memory were found to be a better predictor of survival than KPS (Meyers et al., 2000). Accordingly, the main rationale for brain mapping, the preservation of QoL, is still largely biased by inadequate measures whenever they are used.

\section{Conclusions}

- Some methodological shortcomings derive from the inappropriate transition from epilepsy surgery to tumor surgery.

- Mapping is not a uniform technique, but rather it differs as regards area, function, task, electrical parameters and responses evaluation. Consequently, it requires case-by-case validation.

- The aim is a common methodological framework and personalized intraoperative tasks.

- Mapping the tumor periphery sistematically and mapping impaired patients remain unsolved and difficult tasks.

- Moving from cortical naming-assisted surgical resection to other language and cognitive tasks, poor clinical assessment still limits technical development of tasks and image-guided mapping . 
- Through the use of appropriate methods in the clinical setting and in mapping techniques, surgical removal may safely attack the tumor, starting from the margins.

- Visual inspection allows us to "monitor" normal brain tissue which is to be preserved since functional eloquence is far from known in many areas.

\section{References}

Bartolomeo, P., Thiebaut de Schotten, M. \& Duffau, H. (2007) Mapping of visuospatial functions during brain surgery: a new tool to prevent unilateral spatial neglect. Neurosurgery, Vol.61, No.6, (December 2007), E1340, ISSN 0148-396X

Bauerle K, Greim CA, Schroth M, Geisselbrecht M, Köbler A, Roewer N. Prediction of depth of sedation and anaesthesia by the Narcotrend EEG monitor. British Journal of Anaesthesia, Vol. 92, No. 6, (June 2004), pp.841-845. Epub (April 2004). Erratum in: British Journal of Anaesthesia, Vol.92, No.6, (June 2004), pp.912, ISSN 0007-0912

Bauman, G., Pahapill, P., Macdonald, D., Fisher, B., Leighton, C. \& Cairncross, G. (1999) Low grade glioma: a measuring radiographic response to radiotherapy. Canadian Journal of Neurological Sciences, Vol.26, No.1, (February 1999), pp. 18-22, ISSN: 0317-1671

Bello, L., Gallucci, M., Fava, M., Carrabba, G., Giussani, C., Acerbi, F. et al. (2007) Intraoperative subcortical language tract mapping guides surgical removal of gliomas involving speech areas. Neurosurgery, Vol.60, No.1, (January 2007), pp. 6782, ISSN 0148-396X

Bello, L., Gambini, A., Castellano, A., Carrabba, G., Acerbi, F., Fava, E., Giussani, C., Cadioli, M., Blasi, V., Casarotti, A., Papagno, C., Gupta, AK., Gaini, S., Scotti, G. \& Falini, A. (2008) Motor and language DTI Fiber Tracking combined with intraoperative subcortical mapping for surgical removal of gliomas. Neuroimage, Vol.39, No.1, (January 2008), pp.369-382, ISSN 1053-8119

Benzagmout, M., Gatignol, P. \& Duffau, H. (2007) Resection of World Health Organization Grade II gliomas involving Broca's area: methodological and functional considerations. Neurosurgery, Vol.61. No.4, (October 2007), pp. 741-752, ISSN 0148396X

Berger, M.S., Kincaid, J., Ojemann, G.A. \& Lettich, E. (1989) Brain mapping techniques to maximize resection, safety, and seizure control in children with brain tumors. Neurosurgery, Vol.25, No.5, (November 1989), pp. 786-792, ISSN 0148-396X

Berger, M.S. (1994) Lesions in functional ("Eloquent") cortex and subcortical white matter. Clinical Neurosurgery, Vol.41, pp. 444-463, ISSN 0069-4827, Baltimore

Berkenstadt, H., Perel, A., Hadani, M., Unofrievich, I. \& Ram, Z. (2001) Monitored anesthesia care using remifentanil and propofol for awake craniotomy. Journal of Neurosurgical Anesthesiology, Vol.13, No.3, (July 2001), pp. 246-249, ISSN 0898-4921

Black, P., McL. \& Ronner S.F. (1987) Cortical mapping for defining the limits of tumor resection. Neurosurgery, Vol.20, No.6, (June 1987), pp. 914-919, ISSN 0148-396X

Black, P. (1998) Management of malignant glioma: role of surgery in relation to multimodality therapy. Journal of Neurovirology, Vol.4, No.2, (April 1998), pp. 227236, ISSN: 1355-0284

Bookheimer, S.Y., Zeffiro, T.A., Blaxton, T., Malow, B.A., Gaillard WD, Sato S et al. (1997) A direct comparison of PET activation and electrocortical stimulation mapping for language localization. Neurology, Vol.48, No.4, (April 1997), pp. 1056-1065, ISSN 0028-3878 
Buckner, J.C., Schomberg, P.J., McGinnis, W.L., Cascino, T.L., Scheithauer, B.W., O'Fallon, J.R. et al. (2001) A phase III study of radiation therapy plus carmustine with or without recombinant interferon-alpha in the treatment of patients with newly diagnosed high-grade glioma. Cancer, Vol.92, No.2, (July 2001), pp. 420-433, ISSN $0008-543 \mathrm{X}$

Buckner, J.C. (2003) Factors influencing survival in high-grade gliomas. Seminars in Oncology, Vol.30, No.6, Suppl.19, (December 2003), pp. 10-14, ISSN 0093-7754

Bulsara, K.R., Johnson, J. \& Villavicencio, A.T. (2005) Improvements in brain tumor surgery: the modern history of awake craniotomies. Neurosurgical Focus, Vol.18, No.4, E5, (April 2005), pp. 1-3, ISSN: 1092-0684

Cedzich, C., Taniguchi, M., Schäfer, S. \& Schramm, J. (1996) Somatosensory evoked potential phase reversal and direct motor cortex stimulation during surgery in and around the central region. Neurosurgery, Vol.38, No.5, (May 1996), pp. 962-970, ISSN 0148396X

Cedzich, C., Pechstein, U., Schramm, J. \& Schafer, S. (1998) Electrophysiological considerations regarding electrical stimulation of motor cortex and brain stem in humans. Neurosurgery, Vol.423, No.3, (March 1998), pp. 527-532, ISSN 0148-396X

Chaichana, K.L., McGirt, M.J., Laterra, J., Olivi, A., Quinones- Hiñojosa, A. (2010) Recurrence and malignant degeneration after resection of adult hemispheric lowgrade gliomas. Journal of Neurosurgery, Vol.112, No.1, (January 2010), pp. 10-17, ISSN 0022-3085

Chang, S.M., Parney, I.F., McDermott, M., Barker, F.G. 2nd, Schmidt, M.H., Huang, W. et al. (2003) Perioperative complications and neurological outcomes at first and second craniotomies among patients enrolled in the Glioma Outcome Project. Journal of Neurosurgery, Vol.98, No.6, (June 2003), pp. 1175-1181, ISSN 0022-3085

Corina, D.P., Gibson, E.K., Martin, R., Poliakov, A., Brinkley, J. \& Ojemann, G.A. (2005) Dissociation of action and object naming: evidence from cortical stimulation mapping. Human Brain Mapping, Vol.24, No.1, (January 2005), pp. 1-10, ISSN 10659471

Costello, T.G., Cormack, J.R., Mather, L.E., LaFerlita, B., Murphy, M.A. \& Harris, K. (2005) Plasma levobupivacaine concentrations following scalp block in patients undergoing awake craniotomy. British Journal of Anaesthesia, Vol.94, No.6, (June 2005), pp. 848-851, ISSN 0007-0912

Danks, R.A., Rogers, M., Aglio, L.S., Gugino, L.D. \& Black, P.M. (1998) Patient tolerance of craniotomy performed with the patient under local anaesthesia and monitored conscious sedation. Neurosurgery, Vol.42, No.1, (January 1998), pp. 28-36, ISSN 0148-396X

Duffau, H., Capelle, L., Sichez, J-P., Faillot, T., Abdennour, L., Law Koune, J.D. et al. (1999) Intra-operative direct electrical stimulations of the central nervous system: the Salpêtrière experience with 60 patients. Acta Neurochirurgica (Wien), Vol.141, No.11, (November 1999), pp. 1157-1167, ISSN 0001-6268

Duffau, H., Bauchet, L., Lehéricy, S. \& Capelle, L. (2001) Functional compensation of the left dominant insula for language. Neuroreport, Vol.12, No.10, (July 2001), pp. 21592163, ISSN 0959-4965

Duffau, H., Capelle, L., Denvil, D., Sichez, N., Gatignol, P., Taillandier, L. et al. (2003) Usefulness of intraoperative electrical subcortical mapping during surgery for low- 
grade gliomas located within eloquent brain regions: functional results in a consecutive series of 103 patients. Journal of Neurosurgery, Vol.98, No.4, (April 2003), 764-778, ISSN 0022-3085

Duffau, H., Capelle, L., Denvil, D., Sichez, N., Gatignol, P., Lopes, M. et al (2003) Functional recovery after surgical resection of low grade gliomas in eloquent brain: Hypothesis of brain compensation. Journal of Neurology, Neurosurgery and Psychiatry, Vol.74, No.7, (July 2003), pp. 901-907

Duffau H \& Fontaine D (2005) Successful resection of a left insular cavernous angiomas using neuronavigation and intraoperative language mapping. Acta Neurochirurgica (Wien), Vol.147, No.2, (February 2005), pp. 205-208 ISSN 0001-6268

Duffau, H., Lopes, M., Arthuis, F., Bitar, A., Sichez, J.P., Van Effenterre, R. \& Capelle L. (2005) Contribution of intraoperative electrical stimulations in surgery of low grade gliomas: a comparative study between two series without (1985-96) and with (19962003) functional mapping in the same institution. Journal of Neurology, Neurosurgery and Psychiatry, Vol.76, No.6, (June 2005), pp. 845-851, ISSN 0022-3050

Duffau H. (2005) Intraoperative cortico-subcortical stimulations in surgery of low-grade gliomas. Expert Review of Neurotherapeutics, Vol.5, No.4, (July 2005) pp. 473-85, ISSN: 1473-7175

Duffau, H. (2005) Lessons from brain mapping in surgery for low-grade glioma: insights into associations between tumour and brain plasticity. The Lancet Neurology, Vol.4, No.8, (August 2005), pp. 476-486, ISSN 1474-4422

Duffau, H. (2006) From intraoperative electrical cortico-subcortical cerebral mapping to research on brain's function and plasticity. Rivista Medica, 2006; Vol.12, No.1-2, pp. 15-21, ISSN: 1127-6339

Duffau, H. (2006) New concepts in surgery of WHO grade II glioms: functional brain mapping, connectionism and plasticity. Journal of Neuro-Oncology, Vol.79, No.1, (August 2006), pp. 77-115, ISSN 0167-594X

Duffau, H., Taillandier, L., Gatignol, P. \& Capelle, L. (2006). The insular lobe and brain plasticity: Lessons from tumor surgery. Clinical Neurology and Neurosurgery, Vol.108, No.6, (September 2006), pp. 543-8, ISSN 0303-8467

Duffau, H. (2007) Contribution of cortical and subcortical electrostimulation in brain glioma surgery: methodological and functional considerations. Neurophysiologie Clinique, Vol.37, No.6, (December 2007), pp. 373-82, ISSN 0987-7053

Duffau, H. (2009) A personal consecutive series of surgically treated 51 cases of insular WHO Grade II glioma: advances and limitations. Journal of Neurosurgery, Vol.110, (April 2009), pp. 696-708, ISSN 0022-3085

Ebeling, U., Steinmetz, H., Huang, Y.X. \& Kahn, T. (1989) Topography and identification of the inferior precentral sulcus in MR imaging. AJR. American Journal of Roentgenology, Vol.153, No.5, (November 1989), pp. 1051-1056, ISSN 0361-803X

FitzGerald, D.B., Cosgrove, G.R., Ronner, S., Jiang, H., Buchbinder, B.R., Belliveau, J.W. et al. (1997) Location of language in the cortex: a comparison between functional MR imaging and electrocortical stimulation. AJNR. American Journal of Neuroradiology, Vol.18, No.8, (September 1997), pp. 1529-1539, ISSN 0195-6108

Foerster, O. (1931) The cerebral cortex in man. The Lancet, Vol.218, N.5632, (August 1931), pp. 309-312, ISSN 0140-6736 
Gatignol, P., Capelle, L., Le Bihan, R. \& Duffau, H. (2004) Double dissociation between picture naming and comprehension: an electrostimulation study. Neuroreport, Vol.15, No.1, (January 2004), pp. 191- 195, ISSN 0959-4965

Gharabaghi, A., Fruhmann, B.M., Tatagiba, M. \& Karnath, H.O. (2006) The role of the right superior temporal gyrus in visual search - Insights from intraoperative electrical stimulation. Neuropsychologia, Vol.44, No.12, 2578-2581, ISSN 0028-3932

Gignac, E., Manninen, P.H. \& Gelb, A.W. (1993) Comparison of fentanyl, sufentanil and alfentanil during awake craniotomy for epilepsy. Canadian Journal of Anaesthesia, Vol.40, No.5, Pt .1, (May 1993), pp. 421-424, ISSN 0832-610X

Giovagnoli, A.R. \& Boiardi, A. (1994) Cognitive impairment and quality of life in long-term survivors of malignant brain tumors. Italian Journal of Neurological Sciences, Vol.15, No.9, (December 1994), pp. 481-488, ISSN 0392-0461

Giovagnoli, A.R., Silvani, A., Colombo, E. \& Boiardi, A. (2005) Facets and determinants of quality of life in patients with recurrent high grade glioma. Journal of Neurology, Neurosurgery and Psychiatry, Vol.76, No.4, (April 2005), pp. 562-568, ISSN 0022-3050

Gupta, D.K., Chandra, P.S., Ojha, B.K., Sharma, B.S., Mahapatra, A.K. \& Mehta, V.S. (2007) Awake craniotomy versus surgery under general anesthesia for resection of intrinsic lesions of eloquent cortex- a prospective randomized study. Clinical Neurology and Neurosurgery, Vol.109, No.4, (May 2007), pp. 335-343, ISSN 0303-8467

Gustafsson, M., Edvardsson, T. \& Ahlstrom, G. (2006) The relationship between function, quality of life and coping in patients with low-grade gliomas. Supportive Care in Cancer, Vol.14, No.12, (December 2006), pp. 1205-1212, ISSN 0941-4355

Guthrie, B.L. \& Laws, E.R. Jr. (1990) Supratentorial low-grade gliomas. Neurosurgery Clinics of North America, January Vol.1, No.1, (January 1990), pp. 37-48, ISSN 1042-3680

Haglund, M.M., Ojemann, G.A. \& Hochman, D.W. (1992) Optical imaging of epileptiform and functional activity in human cerebral cortex. Nature, Vol.358, No.6388, pp. 668671, ISSN: 0028-0836

Haglund, M.M., Ojemann, G.A. \& Blasdel, G.G. (1993) Optical imaging of bipolar cortical stimulation. Journal of Neurosurgery, Vol.78, No.5, (May 1993), pp. 785-793, ISSN 0022-3085

Haglund, M.M., Berger, M.S., Shamseldin, M., Lettich, E. \& Ojemann, G.A. (1994) Cortical localization of temporal lobe language sites in patients with gliomas. Neurosurgery, Vol.34, No.4, (April 1994), pp. 567-576, ISSN 0148-396X

Hamberger, M.J., Goodman, R.R., Perrine, K. \& Tammy, T. (2001) Anatomic Dissociation of Auditory and Visual Naming in the Lateral Temporal Cortex. Neurology, Vol.56, No.1, (January 2001), pp.56-61, ISSN 0028-3878

Hamberger, M.J., Seidel, W., Goodman, R.R., Perrine, K. \& McKhann, G.M. (2003) Temporal lobe stimulation reveals anatomic distinction between auditory naming processes. Neurology, Vol.60, pp. 1478-1483, ISSN 0028-3878

Hamberger, M.J., Seidel, W.T., Mckhann, G.M., Perrine, K. \& Goodman, R.R. (2005) Brain stimulation reveals critical auditory naming cortex. Brain, Vol.128, No.11, (November 2005), pp. 2742-2749, ISSN 0006-8950

Hamberger, M.J., McClelland, S., McKhann, G.M. II, Williams, A.C. \& Goodman, R.R. (2007) Distribution of auditory and visual naming sites in nonlesional temporal lobe epilepsy patients and patients with space-occupying temporal lobe lesions. Epilepsia, Vol.48, No.3, (March 2007), pp. 531-538, ISSN 0013-9580 
Hamberger, M.J. (2007) Cortical Language Mapping in Epilepsy: A critical Review. Neuropsychology Review, Vol.17, No.4, (December 2007), pp. 477-489, ISSN 1040-7308

Herholz, K., Thiel, A., Wienhard, K., Pietrzyk, U., von Stockhausen, H.M., Karbe, H. et al (1996) Individual functional anatomy of verb generation. Neuroimage, Vol.3, No.3, (June 1996), pp. 185-194, ISSN 1053-8119

Herholz, K., Reulen, H.J., von Stockhausen, H.M., Thiel, A., Ilmberger, J., Kessler, J. et al (1997) Preoperative activation and intraoperative stimulation of language-related areas in patients with glioma. Neurosurgery, Vol.41, No.6, (December 1997), pp. 1253-1262, ISSN 0148-396X

Herrick, I.A., Craen, R.A., Gelb, A.W., Miller, L.A., Kubu, C.S., Girvin, J.P. et al. (1997) Propofol sedation during awake craniotomy for seizures: patient-controlled administration versus neurolept analgesia. Anesthesia and Analgesia, Vol.84, No.6, (June 1997), pp. 1285-1291, ISSN 0003-2999

Hill, D.L., Smith, A.D., Simmons, A., Maurer, C.R. Jr., Cox, T.C., Elwes, R. et al. (2000) Sources of error in comparing functional magnetic resonance imaging and invasive electrophysiological recordings. Journal of Neurosurgery, Vol.93, No.2, (August 2000), pp. 214-223, ISSN 0022-3085

Himmelseher S, Pfenninger E, Werner C. Intraoperative monitoring in neuroanesthesia: a national comparison between two surveys in Germany in 1991 and 1997. Scientific Neuroanesthesia Research Group of the German Society of Anesthesia and Intensive Care Medicine. Anesthesia and Analgesia, Vol.92, No.1, (January 2001), pp.166-171, ISSN 0003-2999

Huncke, K., Van de Wiele, B., Fried, I. \& Rubinstein, E.H. (1998) The asleep-awake-asleep anesthetic tecnique for intraoperative language mapping. Neurosurgery, Vol.42, No.6, (June 1998),pp. 1312-1316, ISSN 0148-396X

Ilmberger, J., Eisner, W., Schmid, U. \& Reulen, H.J. (2001) Performance in picture naming and word comprehension: evidence for common neuronal substrates from intraoperative language mapping. Brain and Language, Vol.76, No.2, (February 2001), pp. 111-118, ISSN 0093-934X

John J. (1984) Grading of muscle power: comparison of MRC and analogue scales by physiotherapists. Medical Research Council. International Journal of Rehabilitation Research, Vol.7, No.2, (June 1984), pp. 173-181, ISSN: 0342-5282

Kamada, K., Todo, T., Masutani, Y., Aoki, S., Ino, K., Morita, A. \& Saito, N. (2007) Visualization of the frontotemporal language fibers by tractography combined with functional magnetic resonance imaging and magnetoencephalography. Journal of Neurosurgery, Vol.106, No.1, (January 2007), pp. 90-98, ISSN 0022-3085

Keifer, J.C., Dentchev, D., Little, K., Warner, D.S., Friedman, A.H. \& Borel, C.O. (2005) A retrospective analysis of a remifentanil/propofol general anesthetic for craniotomy before awake functional brain mapping. Anesthesia and Analgesia, Vol.101, No.2, (August 2005), pp. 502-508, ISSN 0003-2999

Keles, G.E., Anderson, B., Berger, M.S. (1999) The effect of extent of resection on time to tumor progression and survival in patients with glioblastoma multiforme of the cerebral hemisphere. Surgical Neurology, Vol.52, No.4, (October 1999), pp. 371-379, ISSN 0090-3019

Keles, G.E., Lundin, D.A., Lamborn, K.R., Chang, E.F., Ojemann, G. \& Berger, M.S. (2004) Intraoperative subcortical stimulation mapping for hemispherical perirolandic 
gliomas located within or adjacent to the descending motor pathways: evaluation of morbidity and assessment of functional outcome in 294 patients. Journal of Neurosurgery, Vol.100, No.3, (March 2004), pp. 369-375, ISSN 0022-3085

Keles, G.E. \& Berger, M.S. (2004) Advances in neurosurgical technique in the current management of brain tumors. Seminars in Oncology, Vol.31, No.5, (October 2004), pp. 659-665, ISSN 0093-7754

Kim, S.S., McCutcheon, I.E., Suki, D., Weinberg, J.S., Sawaya, R., Lang, F.F., Ferson, D., Heimberger, A.B., DeMonte, F. \& Prabhu, S.S. (2009) Awake Craniotomy for Brain Tumors Near Eloquent Cortex: Correlation of Intraoperative Cortical Mapping With Neurological Outcomes in 309 Consecutive Patients. Neurosurgery, Vol.64, No.5, (May 2009), pp. 836-846, ISSN 0148-396X

Kombos, T., Suess, O., Ciklatekerlio, O. \& Brock, M. (2001) Monitoring of intraoperative motor evoked potentials to increase the safety of surgery in and around the motor cortex. Journal of Neurosurgery, Vol.95, No.4, (October 2001), pp. 608-614, ISSN 00223085

Kurimoto, M., Asahi, T., Shibata, T., Takahashi, C., Nagai, S., Hayashi, N., Matsui, M. \& Endo, S. (2006) Safe removal of glioblastoma near the angular gyrus by awake surgery preserving calculation ability. Case Report. Neurologia Medico-Chirurgica (Tokyo), Vol.46, No.1, (January 2006), pp. 46-50, ISSN 0470-8105

Lacroix, M., Abi-Said, D., Fourney, D.R., Gokaslan, Z.L., Shi, W., DeMonte, F. et al. (2001) A multivariate analysis of 416 patients with glioblastoma multiforme: prognosis, extent or resection, and survival. Journal of Neurosurgery, Vol.95, No.2, (January 1999), pp. 190-198, ISSN 0022-3085

Little, K. \& Friedman, A.H. (2004) Awake craniotomy for malignant glioma resection. International Congress Series, Vol.1259, (February 2004), pp. 409- 414, ISSN: 05315131

Lu, S., Ahn, D., Johnson, G. \& Cha, S. (2003) Peritumoral diffusion tensor imaging of high grade gliomas and metastatic brain tumors. AJNR. American Journal of Neuroradiology, Vol.24, No.5, (May 2003), pp. 937-941, ISSN 0195-6108

Lu, S., Ahn, D., Johnson, G., Law, M., Zagzag, D. \& Grossman, R.I. (2004) Diffusion-tensor MR imaging of intracranial neoplasia and associated peritumoral edema: introduction of the tumor infiltration index. Radiology, Vol.232, No.1, (July 2004), pp. 221-224, ISSN 0033-8419

Lubrano, V., Roux, F.E. \& Démonet, J.F. (2004) Writing specific sites in frontal areas: a cortical stimulation study. Journal of Neurosurgery, Vol.101, No.5, (November 2004), pp. 787-98, ISSN 0022-3085

Lucas, T.H., McKhann, G.H. \& Ojemann, G.A. (2004) Functional separation of languages in the bilingual brain: A comparison of electrical stimulation language mapping in 25 bilingual patients and 117 monolingual control patients. Journal of Neurosurgery, Vol.101, No.3, (September 2004), pp. 449-457, ISSN 0022-3085

Lüders, H.O., Lesser, R.P., Dinner, D.S., Morris, H.H., Wyllie, E., Godoy, J. (1988) Localization of cortical function: new information from extraoperative monitoring of patients with epilepsy. Epilepsia, Vol.29 , Suppl.2, pp. S56-65, ISSN 0013-9580

Lüders, H.O., Lesser, R.P., Hahn, J., Dinner, D.S., Morris, H.H., Wyllie, E. \& Godoy, J. (1991) Basal Temporal Language Area. Brain, Vol.114, No.2, (April 1991), pp. 743-754, ISSN 0006-8950 
Malow, B.A., Blaxton, T.A., Sato, S., Bookheimer, S.Y., Kufta, C.V., Figlozzi, C.M. \& Theodore, W.H. (1996). Cortical stimulation elicits regional distinctions in auditory and visual naming. Epilepsia, Vol.37, No.3, (March 1996), pp. 245-52, ISSN 00139580

Matz, P.G., Cobbs, C. \& Berger, M.S. (1999) Intraoperative cortical mapping as a guide to the surgical resection of gliomas. Journal of Neuro-Oncology, Vol.42, No.3, (May 1999), pp. 233-245, ISSN 0167-594X

McGirt, M.J., Chaichana, K.L., Attenello, F.J., Weingart, J.D., Than, K., Burger, P.C. et al. (2008) Extent of surgical resection is independently associated with survival in patients with hemispheric infiltrating low-grade gliomas. Neurosurgery, Vol.63, No.4, pp. 700-708, ISSN 0148-396X

Meyer, F.B., Bates, L.M., Goerss, S.J., Friedman, J.A., Windschiti W.L., Duffy, J.R., Perkins W.J. \& O'Neill, B.P. (2001) Awake craniotomy for aggressive resection of primary gliomas located in eloquent brain. Mayo Clinic Proceedings, Vol.76, No.7, (July 2001), pp. 677-687, ISSN 0025-6196

Meyers, C.A., Hess, K.R., Yung, W.K.A. \& Levin, V.A. (2000) Cognitive function as a predictor of survival in patients with recurrent malignant glioma Journal of Clinical Oncology, Vol.18, Nr.3, (February 2000), pp. 646-650, ISSN 0732-183X

Milea, D., Lobel, E., Lehéricy, S., Duffau, H., Rivaud-Péchoux, S., Berthoz, A. \& PierrotDeseilligny, C. (2002) Intraoperative frontal eye field stimulation elicits ocular deviation and saccade suppression. Neuroreport, Vol.13, No.10, (July 2002), pp. 1359-1364, ISSN: 0959-4965

Nariai, T., Sato, K., Hirakawa, K., Ohta, Y., Tanaka, Y., Ishiwata, K. et al. (2005) Imaging of somatotopic representation of sensory cortex with intrinsic optical signals as guides for brain tumor surgery. Journal of Neurosurgery, Vol.103, No.3, (September 2005), pp. 414-423, ISSN 0022-3085

Neuloh, G. \& Schramm, J. (2002) Mapping and monitoring of supratentorial procedures. In: Neurophysiology in neurosurgery: a modern intraoperative approach. Deletis V, Shils J (eds), pp 339-404, Academic Press, San Diego

Neuloh, G. \& Schramm, J. (2004) Motor evoked potential monitoring for the surgery of brain tumours and vascular malformations. Advances and Technical Standards in Neurosurgery, Vol.29, (January 2004), pp. 171-228, ISSN: 0095-4829

Ojemann, G.A. (1977) Language and verbal memory functions during and after human thalamic stimulation. Neurología, Neurocirugía y Psiquiatría, Vol.18, Suppl.2-3, pp. 35-45, ISSN 0028-3851

Ojemann, G.A. (1979). Individual variability in cortical localization of language. Journal of Neurosurgery, Vol.50, No.2, (February 1979), pp. 164-169, ISSN 0022-3085

Ojemann, G.A. \& Mateer, C. (1979) Human language cortex: Localization of memory, syntax, and sequential motor-phoneme identification systems. Science, Vol.205, No.4413, (September 1979), pp. 1401-1403, ISSN 0036-8075

Ojemann, G.A. (1983) Brain organization for language from the perspective of electrical stimulation mapping. The Behavioural and Brain Sciences, Vol.6 pp. 189- 230, ISSN 0140-525X

Ojemann, G.A. \& Dodrill, C.B. (1985) Verbal memory deficits after left temporal lobectomy for epilepsy. Mechanism and intraoperative prediction. Journal of Neurosurgery, Vol.62, No.1, (January 1985), pp. 101-107, ISSN 0022-3085 
Ojemann, G.A., Ojemann, J., Lettich, E. \& Berger, M. (1989) Cortical language localization in left, dominant hemisphere. An electrical stimulation mapping investigation in 117 patients. Journal of Neurosurgery, Vol.71, No.3, (September 1989), pp. 316-326, ISSN 0022-3085

Ojemann, G.A. (1989) Some brain mechanism for reading. Brain And Reading, C von Euler (Ed), pp. 47-59, Macmillan, New York

Ojemann, G.A. (2003) The neurobiology of language and verbal memory: observations from awake neurosurgery. International Journal of Psychophysiology, Vol.48, No.2, (May 2003), pp. 141-146, ISSN 0167-8760

Ojemann, J.G., Ojemann, G.A. \& Lettich, E. (2002) Cortical stimulation mapping of language cortex by using a verb generation task: effects of learning and comparison to mapping based on object naming. Journal of Neurosurgery, Vol.97, No.1, (July 2002), pp. 33-38, ISSN: 0022-3085

Ojemann, S.G., Berger, M.S., Lettich, E. \& Ojemann, G.A. (2003) Localisation of language function in children: results of electrical stimulation mapping. Journal of Neurosurgery, Vol.98, No.3, (March 2003), pp. 465-470, ISSN 0022-3085

Påhlson, A., Ek, L., Ahlström, G. \& Smits, A. (2003) Pitfalls in the Assessment of disability in individuals with low-grade gliomas. Journal of Neuro-Oncology, Vol.65, No.2, (November 2003), pp. 149-158, ISSN 0167-594X

Papanicolaou, A.C., Simos, P.G., Breier, J.I., Zouridakis, G., Willmore, L.J., Wheless, J.W. et al. (1999) Magnetoencephalographic mapping of the language-specific cortex. Journal of Neurosurgery, Vol.90, No.1, (January 1999), pp. 85-93, ISSN 0022-3085

Penfield, W. \& Boldrey, E. (1937) Somatic motor and sensory representation in the cerebral cortex of man as studied by electrical stimulation. Brain, Vol.60, No.4, (December 1937), pp. 389-443, ISSN 0006-8950

Penfield, W. \& Erickson, T.C. (1942) Epilepsy and Cerebral Localization. A Study of the Mechanism, Treatment, and Prevention of Epileptic Seizures. Archives of Internal Medicine, Vol.70, No.5, (November 1942), pp. 916-917, ISSN 0003-9926

Penfield, W. \& Rasmussen, T. (1950) Secondary sensory and motor representation. In: The cerebral cortex of man, pp 109-134, MacMillan, New York

Peraud, A., Ilmberger, J. \& Reulen, H-J. (2004) Surgical resection of gliomas WHO grade II and III located in the opercular region. Acta Neurochirurgica (Wien), Vol.146, No.1, (January 2004), pp. 9-18, ISSN 0001-6268

Petrovich Brennan, N.M., Whalen, S., de Morales Branco, D., O'Shea, J.P., Norton, I.H. \& Golby, A.J. (2007) Object naming is a more sensitive measure of speech localization than number counting: converging evidence from direct cortical stimulation and fMRI. NeuroImage, 2007; Vol.37: Suppl.1, (May 2007), pp. S100-S108, ISSN 1053-8119

Picht, T., Kombos, T., Gramm, H.J., Brock, M. \& Suess, O. (2006) Multimodal protocol for awake craniotomy in language cortex tumour surgery. Acta Neurochirurgica (Wien), Vol.148, No.2, (February 2006), pp. 127-137, ISSN 0001-6268

Pouration, N., Bookheimer, S.Y., Rex, D.E., Martin, N.A. \& Toga, A.W. (2002) Utility of preoperative functional magnetic resonance imaging for identifying language cortices in patients with vascular malformations. Journal of Neurosurgery, Vol.97, No.1, (July 2002), pp. 21-32, ISSN 0022-3085

Pouratian, N., Bookheimer, S.Y., Rubino, G., Martin, N.A. \& Toga, A.W. (2003) Categoryspecific naming deficit identified by intraoperative stimulation mapping and 
postoperative neuropsychological testing. Journal of Neurosurgery, Vol.99, No.1, (July 2003), pp. 170-176, ISSN 0022-3085

Pouratian, N., Cannestra, A.F., Bookheimer, S.Y., Martin, N.A. \& Toga, A.W. (2004) Variability of intraoperative electrocortical stimulation mapping parameters across and within individuals. Journal of Neurosurgery, Vol.101, No.3, (September 2004), pp. 458-466, ISSN 0022-3085

Price, S.J., Burnet, N.G., Donovan, T., Green, H.A.L., Pena, A., Antoun, N.M. et al. (2003) Diffusion tensor imaging of brain tumors et 3T: a potential tool for assesing whait matter tract invasion? Clinical Radiology, 2003; Vol.58, No.6, (June 2003), pp. 455-462, ISSN 0009-9260

Quiñones-Hinojosa, A., Ojemann, S.G., Sanai, N., Dillon, W.P. \& Berger, M.S. (2003) Preoperative correlation of intraoperative cortical mapping with magnetic resonance imaging landmarks to predict localization of the Broca area. Journal of Neurosurgery, Vol.99, No.2, (August 2003), pp. 311-318, ISSN 0022-3085

Ranck, J.B. Jr. (1975) Which elements are excited in electrical stimulation of mammalian central nervous system: a review. Brain Research, Vol.98, No.3, (November 1975), pp. 417-440, ISSN 0006-8993

Reithmeier, T., Krammer, M., Gumprecht, H., Gerstner, W. \& Lumenta, C.B. (2003) Neuronavigation combined with electrophysiological monitoring for surgery of lesions in eloquent brain areas in 42 cases: a retrospective comparison of the neurological outcome and the quality of resection with a control group with similar lesions. Minimally Invasive Neurosurgery, Vol.46, No.2, (April 2003), pp. 65-71, ISSN 0946-7211

Roux, F-E. \& Trémoulet, M. (2002) Organization of language areas in bilingual patients: a cortical stimulation study. Journal of Neurosurgery, 2002 Oct; Vol.97, No.4, (October 2002), pp. 857-864, ISSN 0022-3085

Roux, F-E., Boulanouar, K., Lotteri, J.A., Mejdoubi, M., LeSage, J.P. \& Berry, I. (2003) Language functional magnetic resonance imaging in preoperative assessment of language areas: correlation with direct cortical stimulation. Neurosurgery, Vol.52, No.6, (June 2003), pp. 1335-1347, ISSN 0148-396X

Roux, F-E., Boetto, S., Sacko, O., Chollet, F. \& Tremoulet, M. (2003) Writing, calculating and finger recognition in the region of the angular gyrus: a cortical stimulation study of Gerstmann syndrome. Journal of Neurosurgery, Vol.99, No.4, (October 2003), pp. 716727, ISSN 0022-3085

Roux, F-E., Lubrano, V., Lauwers-Cances, V., Trémoulet, M., Mascott, C.R. et al. (2004) Intra-operative mapping of cortical areas involved in reading in mono- and bilingual patients. Brain, Vol.127, No.8, (August 2004), pp. 1796-1810, ISSN 00068950

Ruge, M.I., Victor, J., Hosain, S., Correa, D.D., Relkin, N.R., Tabar, V., Brennan, C., Gutin, P.H. \& Hirsch, J. (1999) Concordance between functional magnetic resonance imaging and intraoperative language mapping. Stereotactic and Functional Neurosurgery, Vol.72, No.2-4, (July 1999), pp. 95-102, ISSN 1011-6125

Rutten, G.J., Van Rijen, P.C., Van Veelen, C.W.M. \& Ramsey, N.F. Language area localization with three-dimensional functional magnetic resonance imaging matches intrasulcal electrostimulation in Broca's area. Annals of Neurology, Vol.46, No.3, (September 1999), pp. 405-408, ISSN 0364-5134 
Rutten, G.J., Ramsey, N.F., van Rijen, P.C., Noordmans, H.J. \& van Veelen, W.M. (2002) Development of a functional magnetic resonance imaging protocol for intraoperative localization of critical temporoparietal language areas. Annals of Neurology, Vol.51, No.3, (March 2002), pp. 350-360, ISSN 0364-5134

Sahjpaul, R.L. (2000) Awake craniotomy: controversies, indication and techniques in the surgical treatment of temporal lobe epilepsy. Canadian Journal of Neurological Sciences, Vol.27, Suppl.1, (May 2000), pp. 55-63, discussion pp, 92-96, ISSN 03171671

Sanai N, Mirzadeh Z, Berger MS. Functional outcome ater language mapping for glioma resection. The New England Journal of Medicine, Vol.358, No.1, (January 2008), pp. 1827, ISSN 0028-4793

Sanai, N., Polley, M.Y. \& Berger, M.S. (2010) Insular glioma resection: assessment of patient morbidity, survival, and tumor progression. Clinical article. Journal of Neurosurgery, Vol.112, No.1, (January 2010), pp. 1-9, ISSN 0022-3085

Sarang, A. \& Dinsmore, J. Anaesthesia for awake craniotomy - evolution of a technique that facilitates awake neurological testing. British Journal of Anaesthesia, Vol.90, No.2, (February 2003), pp. 161-165, ISSN 0007-0912

Sawaya, R., Hammoud, M., Schoppa, D., Hess, K.R., Wu, S.Z., Shi, W-M. \& Wuildrick, D.M. (1998) Neurosurgical outcomes in a modern series of 400 craniotomies for treatment of parenchymal tumors. Neurosurgery, Vol.42, (May 1998), pp. 1044-1056, ISSN 0148-396X

Sawaya, R., Hammoud, M.A., Ligon, B.E. \& Fuller, G.N. (1999) Intraoperative localization of tumor and margins, In: The Gliomas, Berger, M.S. \& Wilson, C.B. (Ed.), pp. 361-375, Saunders W.B., ISBN-10: 0721648258/ISBN-13: 978-0721648255, Philadelphia

Schäffler, L., Lüders, H.O. \& Beck, G.J. (1996) Quantitative comparison of language deficits produced by extraoperative electrical stimulation of Broca's Wernicke's and Basal Temporal Language areas. Epilepsia, Vol.37, No.5, (May 1996), pp. 463- 475, ISSN 0013-9580

Schwartz, T.H., Devinsky, O., Doyle, W. \& Perrine, K. (1999) Function-Specific highprobability "nodes" identified in posterior language cortex. Epilepsia, Vol.40, No.5, (May 1999), pp. 575-583, ISSN 0013-9580

Seeck, M., Pegna ,A.J., Ortigue, S., Spinelli, L., Dessibourg, C.A., Delavelle, J. et al. (2006) Speech arrest with stimulation may not reliably predict language deficit after epilepsy surgery. Neurology, 2006 Feb; Vol.66, No.4, (February 2006), pp. 592-594, ISSN 0028-3878

Seitz, R.J., Huang, Y., Knorr, U., Tellmann, L., Herzog, H. \& Freund, H.J. (1995) Large-scale plasticity of the human motor cortex. Neuroreport, Vol.6, No.5, (March 1995), pp. 742-744, ISSN 0959-4965

Serletis, D. \& Bernstein, M. (2007) Prospective study of awake craniotomy used routinely and nonselectively for supratentorial tumors. Journal of Neurosurgery, Vol.107, No.1, (July 2007), pp. 1-6, ISSN 0022-3085

Signorelli, F., Guyotat, J., Isnard, J., Schneider, F., Mohammedi, R. \& Bret, P. (2001) The value of cortical stimulation applied to the surgery of malignant gliomas in language areas. Neurological Sciences, Vol.22, No.1, (April 2001), pp. 3-10, ISSN: 1590-1874 
Silbergeld, D.L., Mueller, W.M., Colley, P.S., Ojemann, G.A. \& Lettich, E. (1992) Use Propofol (Diprivan) for awake craniotomies: technical note. Surgical Neurology, Vol.38, No.4, (October 1992), pp.271-272, ISSN 0090-3019

Simon, M., Neuloh, G., von Lehe, M., Meyer, B., Schramm, J. (2009) Insular gliomas: the case for surgical management. Journal of Neurosurgery, Vol.110, No.4, (April 2009), pp. 685-695, ISSN 0022-3085

Simos, P.G., Papanicolaou, A.C., Breier, J.I., Wheless, J.W., Constantinou, J.E.C., Gormley, W.B. \& Maggio, W.W. (1999) Localization of language-specific cortex by using magnetic source imaging and electrical stimulation mapping. Journal of Neurosurgery, Vol.91, No.5, (November 1999), pp. 787-796, ISSN 0022-3085

Skirboll, S.S., Ojemann, G.A., Berger, M.S., Lettich, E. \& Winn, R. (1996) Functional cortex and subcortical white matter located within gliomas. Neurosurgery, Vol.38, No.4, (April 1996), pp. 678-684, ISSN 0148-396X

Skucas, A.P. \& Artru, A.A. (2006) Anesthetic complications of awake craniotomies for epilepsy surgery. Anesthesia and Analgesia, Vol.102, No.3, (March 2006), pp. 882-887, ISSN 0003-2999

Smith, J.S., Chang, E.F., Lamborn, K.R., Chang, S.M., Prados, M.D., Cha, S., et al. (2008) Role of extent of resection in the long-term outcome of low-grade hemispheric gliomas. Journal of Clinical Oncology Vol.26, No.8, (March 2008), pp. 1338-1345,ISSN: 15277755

Stadlbauer, A., Moser, E., Gruber, S., Buslei, R., Nimscki, C., Fahlbusch, R. \& Ganslandt, O. (2004) Improved delination of brain tumors: an automated method for segmentation based on pathologic changes of 1HMRSI metabolites in gliomas. Neuroimage, Vol.23, No.2, (October 2004), pp. 454-461, ISSN 1053-8119

Stadlbauer, A., Gruber, S., Nimscki, C. et al. (2006) Preoperative grading of gliomas using metabolite quantification with high-spatial-resolution proton MR spectrospic imaging. Radiology, Vol.238, No.3, (March 2006) pp. 958-969, ISSN 0033-8419

Stummer, W., Pichlmeier, U., Meinel, T., Wiestler, O.D., Zanella, F. \& Reulen, H-J. for the ALA-Glioma Study Group (2006) Fluorescence-guided surgery with 5aminolevulinic acid for resection of malignant glioma: a randomised controlled multicentre phase III trial. The Lancet Oncology, Vol.7, No.5, (April 2006), pp.392401, ISSN: $1470-2045$

Talacchi, A., Turazzi, S., Locatelli, F., Sala, F., Beltramello, A., Alessandrini, F., Manganotti, P., Lanteri, P., Gambin, R., Ganau, M., Tramontano, V., Santini, B. \& Gerosa, M. (2010) Surgical treatment of high-grade gliomas in motor areas. The impact of different supportive technologies: a 171-patient series. Journal of Neuro-Oncology, (April 2010), DOI 10.1007/s11060-010-0193-x

Talacchi, A., Santini, B., Savazzi, S. \& Gerosa M. (2010) Cognitive effects of tumour and surgical treatment in glioma patients. Journal of Neuro-Oncology, (September 2010), DOI 10.1007/s11060-010-0417-0

Talos, I.F., Zou, K.H., Kikinis, R. \& Jolesz, F.A. (2007) Volumetric assessment of tumor infiltration of adjacent white matter based on anatomic MRI and diffusion tensor tractography. Academic Radiology, Vol.14, No.4, (April 2007), pp. 431-436, ISSN 1076-6332

Taphoorn, M.J.B., Heimans, J.J., Snoek, F.J., Lindeboom, J., Oosterink, B., Wolbers, J.G. \& Karim, A.B.M. (1992) Assessment of quality of life in patients treated for low-grade 
glioma: a preliminary report. Journal of Neurology, Neurosurgery and Psychiatry, Vol.55, No.5, (May 1992), pp. 372- 376, ISSN 0022-3050

Taphoorn, M.J.B. \& Klein, M. (2004) Cognitive Status in adult patients with brain tumours. The Lancet Neurology, Vol.3, No.3, (March 2004), pp. 159-168, ISSN 1474-4422

Taphoorn, M.J.B., Stupp, R., Coens, C., Osaba, D., Kortmann, R., Van den Bent, M.J., Mason, W. et al. (2005) Health-related qualità of life in patients with glioblastoma: a randomised controlled trial. The Lancet Oncology, Vol.6, No.12, (December 2005), pp. 934-944, ISSN: 1470-2045

Taylor, M.D. \& Bernstein, M. (1999) Awake craniotomy with brain mapping as the routine surgical approach to treating patients with supratentorial intaaxial tumors: a prospective trial of 200 cases. Journal of Neurosurgery, Vol.90, No.1, (January 1999), pp. 35-41, ISSN 0022-3085

Taylor, W.A., Thomas, N.W., Wellings, J.A. \& Bell, BA. (1995) Timing of postoperative intracranial hematoma development and implications for the best use of neurosurgical intensive care. Journal of neurosurgery, Vol.82, No.1, (January 1995), pp. 48-50, ISSN 0022-3085

Thiebaut de Schotten, M., Urbanski, M., Duffau, H., Volle, E., Lévy, R., Dubois, B. \& Bartolomeo, P. (2005) Direct evidence for a parietal pathway subserving spatial awareness in humans. Science, Vol.309, No.5744, (September 2005), pp. 2226- 2228, ISSN 0036-8075

Toms, S.A., Ferson, D.Z. \& Sawaya, R. (1999) Basic surgical techniques in the resection of malignant gliomas. Journal of Neuro-Oncology, Vol.42, No.3, (May 1999), pp. 215-226, ISSN 0167-594X

Tucha, O., Smeley, C., Preier, M. \& Lange, K,W. Cognitive Deficits Before and After with Brain Tumours. Neurosurgery, 2000; Vol.47, No.2, (August 2000), pp. 324- 334, ISSN 0148-396X

Van Buren, J.M., Fedio, P. \& Frederick, G.C. (1978) Mechanisms and localization of speech in the parietotemporal cortex. Neurosurgery, Vol.2, No.3, (May-June 1978), pp. 233-239, ISSN 0148-396X

Vives, K.P. \& Piepmeier, J.M. (1999) Complications and expected outcome of glioma surgery. Journal of Neuro-Oncology, Vol.42, No.3, ( May 1999), pp. 289-302, ISSN 0167-594X

Waydo, S., Kraskov, A., Quian Quiroga, R., Fried, I. \& Koch, C. (2006) Sparse Representation in the Human Medial Temporal Lobe. The Journal of Neuroscience, Vol.26, No.40, (Ottobre 2006), pp. 10232-10234, ISSN: 0888-0395

Weitzner, M.A., Meyers, C.A. \& Byrne, K. (1996) Psychosocial functioning and quality of life in patients with primary brain tumours. Journal of Neurosurgery, Vol.84, No.1, (January 1996), pp. 29-34, ISSN 0022-3085

Weitzner, M.A. \& Meyers, C.A. (1997) Cognitive Functioning and quality of life in malignant glioma patients: a review of literature. Psycho-Oncology, Vol.6, No.3, (September 1997), pp. 169-177, ISSN 1057-9249

Whittle, I.R., Borthwick et al (2003) Brain dysfunction following 'awake' craniotomy, brain mapping and resection of glioma. British Journal of Neurosurgery, April, Vol.17, No.2, (April 2003), pp. 130- 137, ISSN 0007-0912 
Whittle, I.R., Midgley, S., Georges, H., Pringle, A.M. \& Taylor, R. (2005) Patient perceptions of "awake" brain tumour surgery. Acta Neurochirurgica (Wien), Vol.147, No.3, (March 2005), pp. 275-277, ISSN 0001-6268

Wiedemayer, H., Sandalcioglu, I.E., Armbruster, W., Regel, J., Schaefer, H. \& Stolke, D. (2004) False negative findings in intraoperative SEP monitoring: analysis of 658 consecutive neurosurgical cases and review of published reports. Journal of Neurology, Neurosurgery and Psychiatry, Vol.75, No.2, (February 2004), pp. 280-286, ISSN 0022-3050

Wu, J.S., Zhou, L.F., Tang, W.J., Mao, Y., Hu, J., Song, Y.Y. et al (2007) Clinical evaluation and follow-up outcome of diffusion tensor imaging-based functional neuronavigation: a prospective, controlled study in patients with gliomas involving pyramidal tracts. Neurosurgery, Vol.61, No.5, (November 2007), pp. 935-949, ISSN 0148-396X

Yaşargil, M.G. (1996) Neuropathology, In: Microneurosurgery, Vol IVA. Yaşargil MG (Ed), pp. 115-188, Thieme, New York

Yaşargil, M.G. (1996) Surgical approaches, In: Microneurosurgery, Vol IVB. Yaşargil MG (Ed), pp. 29-68, Thieme, New York

Yaşargil, M.G. (1996) Strategies, tactics and Techniques, In: Microneurosurgery, Vol IVB. Yaşargil MG (Ed), pp. 69-91, Thieme, New York

Yaşargil, M.G., Kadri, P.A. \& Yaşargil, D.C. (2004) Microsurgery for malignant gliomas. Journal of Neuro-Oncology, Vol.69, No.1, (August-Sptember 2004), pp. 67-81, ISSN 0167-594X

Yoshii, Y., Tominaga, D., Sugimoto, K., Tsuchida, Y., Hyodo, A., Yonaha, H. \& Kushi, S. (2008) Cognitive function of patients with brain tumor in pre- and postoperative stage. Surgical Neurology, Vol.69, No.1, (January 2008) pp. 51-61, ISSN 0090-3019 


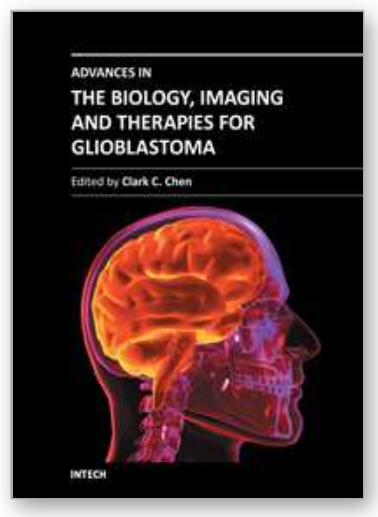

\author{
Advances in the Biology, Imaging and Therapies for Glioblastoma \\ Edited by Prof. Clark Chen
}

ISBN 978-953-307-284-5

Hard cover, 424 pages

Publisher InTech

Published online 09, November, 2011

Published in print edition November, 2011

This book is intended for physicians and scientists with interest in glioblastoma biology, imaging and therapy. Select topics in DNA repair are presented here to demonstrate novel paradigms as they relate to therapeutic strategies. The book should serve as a supplementary text in courses and seminars as well as a general reference.

\title{
How to reference
}

In order to correctly reference this scholarly work, feel free to copy and paste the following:

Andrea Talacchi, Giovanna Maddalena Squintani, Barbara Santini, Francesca Casagrande, Francesco Procaccio, Franco Alessandrini, Giada Zoccatelli, Vincenzo Tramontano, Aurel Hasanbelliu and Massimo Gerosa (2011). Surgical Treatment of Supratentorial Glioma in Eloquent Areas, Advances in the Biology, Imaging and Therapies for Glioblastoma, Prof. Clark Chen (Ed.), ISBN: 978-953-307-284-5, InTech, Available from: http://www.intechopen.com/books/advances-in-the-biology-imaging-and-therapies-forglioblastoma/surgical-treatment-of-supratentorial-glioma-in-eloquent-areas

\section{INTECH}

open science | open minds

\section{InTech Europe}

University Campus STeP Ri

Slavka Krautzeka 83/A

51000 Rijeka, Croatia

Phone: +385 (51) 770447

Fax: +385 (51) 686166

www.intechopen.com

\section{InTech China}

Unit 405, Office Block, Hotel Equatorial Shanghai

No.65, Yan An Road (West), Shanghai, 200040, China

中国上海市延安西路 65 号上海国际贵都大饭店办公楼 405 单元

Phone: +86-21-62489820

Fax: +86-21-62489821 
(C) 2011 The Author(s). Licensee IntechOpen. This is an open access article distributed under the terms of the Creative Commons Attribution 3.0 License, which permits unrestricted use, distribution, and reproduction in any medium, provided the original work is properly cited. 